\section{$m(6) \sqrt{n}$ \\ andm}

\section{N04 171978}

This is a Library Círculating Copy which may be borrowed for two weeks. For a personal retention copy, call Tech. Info. Dívision, Ext. 6782

\title{
and Environment Division
}

\section{4

Utility Investment In On-Site Solar: Risk And Return Analysis For Capitalization And Financing
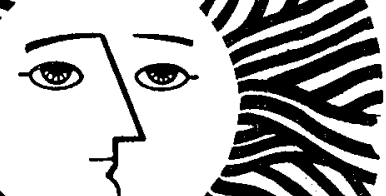

Edward Kabn and Stephen Schutz 


\section{LEGAL NOTICE}

This report was prepared as an account of work sponsored by the United States Government. Neither the United States nor the Department of Energy, nor any of their employees, nor any of their contractors, subcontractors, or their employees, makes any warranty, express or implied, or assumes any legal liability or responsibility for the accuracy, completeness or usefulness of any information, apparatus, product or process disclosed, or represents that its use would not infringe privately owned rights.

Printed in the United States of America

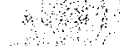

Available from

National Technical Information Service

U. S. Department of Commerce

5285 Port Royal Road

Springfield, VA 22161

Price: Printed Copy, \$ 5.25 Domestic; $\$ 10.50$ Foreign

Microfiche, \$3.00 Domestic; \$4.50 Foreign 


\section{UTILITY INVESTMENT IN ON-SITE SOLAR:}

RISK AND RETURN ANALYSIS FOR

CAPITALIZATION AND FINANCING

Edward Kahn

Stephen Schutz

September, 1978

Energy Analysis Program

Energy and Environment Division

Lawrence Berkeley Laboratory

Berkeley, California 94720 


\section{Table of Contents}

Acknowledgments . . . . . . . . . . . . . . . . . . v

1.0 Introduction . . . . . . . . . . . . . . . . . . 1

1.1 Argument in Brief ................. . 1

1.2 Outline of the Analysis . . . . . . . . . . . . 3

2.0 The Capital Asset Pricing Mode1 . . . . . . . . . . 3

2.1 Definitions and Examples . . . . . . . . . . . 3

2.2 The Historical Record . . . . . . . . . . . 7

2.3 Application to Utility Equity Returns . . . . . . . . 9

2.4 Project Evaluation . . . . . . . . . . . . . 10

3.0 Regulatory Applications . . . . . . . . . . . . . . 12

3.1 Rate of Return Calculations . . . . . . . . . . 13

3.2 The Financing Option . . . . . . . . . . . . . 15

3.3 The Capitalization Option . . . . . . . . . . . . 17

4.0 Empirical Results . . . . . . . . . . . . . . . . 19

4.1 CAPM Applied to Utility Securities . . . . . . . . . 20

4.2 Estimating Beta for Utility Investment in On-Site Solar . . . . . . . . . . . . . . 21

4.2.1 Default Risk . . . . . . . . .........._._ 21

4.2.2 Conventiona1 Utility Risks . . . . . . . . 22

4.2.3 Preliminary Comparisons . . . . . . . 25

5.0 Determinants of Asset Betas . . . . . . . . . . . 26

5.1 Elasticity of Expectations Mode1 . . . . . . . . 27

5,2 Coa1 vs. Nuclear: An Example of Capital Charge Differentials . . . . . . . . . . 28

5.3 The Lemon Technology Problem . . . . . . . . . . . . 29

5.4 An Alternate Approach . . . . . . . . . . . . 29

6.0 Conclusion . . . . . . . . . . . . . . . . . 30

References . . . . . . . . . . . . . . . . . . 33

Appendix 1. Derivation of CAPM . . . . . . . . . . . . 35

Appendix 2. Risk Measure for Projects . . . . . . . . . . . 37

Appendix 3. The Procedure Used in the Calculation of the Systematic Risk Measure B . . . . . . . . 41

Appendix 4. The Stability of Technical B . . . . . . . . . 47

Appendix 5. Determination of $\beta$ for On-Site Solar Heating . . . 50 


\section{List of Figures}

Fig. 1. Capital Market Line . . . . . . . . . . . . . 5

Fig. 2. Theoretical vs. Actual Security Market Line . . . . 8

Fig. Al. Variation of Beta Over Time ( 60 month Intervals). . . 43

Fig. A2. Beta for Standard and Poor's Utility Index . . . . . 44

Fig. A3. San Diego Gas \& Electric Co. Beta . . . . . . . . . 45

Fig. A4. Pacific Gas \& Electric Co. Beta . . . . . . . . . . . 46

Fig. A5. Beta Scatter as a Function of Averaging Interva1: Utilities Index. . . . . . . . . . . . . 48

Fig. A6. Beta Scatter as a Function of Averaging Interva1: Pacific Gas \& Electric . . . . . . . . . . 49

Fig. A7. Housing Occupancy Rate Regressed on Stock Market Index Rate of Return . . . . . . . . . . . . . 52

Fig. A8. Bond Index Rate of Return Regressed on Stock Market Index Rate of Return . . . . . . . . . . . 53

\section{List of Tables}

Table 1. Internal Rate of Return as a Function of Region, System Lifetime and Taxation... . . . . . . . 16

Tab1e 2. Fixed Charge Rates - Coal vs. Nuclear . . . . . . 32 


\section{ACKNOWLEDGMENTS}

This work was supported by the Barriers and Incentives Branch in the Office of the Assistant Secretary for Conservation and Solar Applications, U.S. Department of Energy. The authors would like to thank Dr. Roger Bezdek for his encouragement and support. Leonard Ross and Dan Kirschner provided insightful criticism and constructive suggestions at several points in our investigation. We also received assistance, advice and encouragement from Arthur Sirkin and Menasha Tausner, New Jersey Department of the Public Advocate; James Cherry, California Public Utilities Commission; Barr Rosenberg, Menachem Brenner, Robert Meyer, Fred Balderston, and Austin Hoggatt of the University of California, Berkeley, Graduate School of Business Administration. Responsibility for remaining errors rests with the authors. 
UTILITY INVESTMENT IN ON-SITE SOLAR:

RISK AND RETURN ANALYSIS FOR CAPITALIZATION AND FINANCING

\section{INTRODUCTION}

This is a study of a set of financial strategies designed to accelerate the penetration of on-site solar heating and cooling systems. The role of financial intermediary in this analysis is played by the local regulated public utility. On site solar systems would either be owned outright by utilities and capitalized in their rate base or such projects would be financed by the utility acting as a limited purpose banker. There is widespread interest in this kind of strategy. Such interest was expressed recently for example in the report of the Office of Technology Assessment, Application of Solar Technology to Today's Energy Needs, v.1 (June, 1978). The issues surrounding these proposals are complex. Many are legal or regulatory in nature, involving questions of competition and monopoly, rate discrimination, tax regulation and so on. These are taken up in

some detail in an accompanying analysis.

Surprising1y little effort has been directed at understanding the economic basis of utility solar finance or ownership. Yet at the heart of these proposals there is usually a set of assertions concerning the low cost and high volume of capital available to utilities which would make these schemes economically attractive. What is needed is a general framework in which various financing alternatives can be evaluated quantitatively. This means that the determinants of the cost of capital for such projects must be explicitly analyzed so that plausible schemes can be compared.

1.1 The Argument in Brief

In the discussion which follows these questions will be addressed using the approach of portfolio theory or the capital asset pricing 
model (CAPM). In this paradign the cost of capital is estimated by looking at the market-oriented risk associated with a project and linking this to an estimated market price of risk to compute the appropriate capital charge. The underlying perspective of CAPM approach is the quantification of the value of diversification.

We will be able to use the CAPM to capture the insurance or diversification benefit of on-site solar systems which is difficult to express in the consumer decision framework. An individual's calculation of the economic return on the investment in on-site solar heating cannot easily quantify the value of this technology as a hedge against future oil embargos, macro-economic fluctuation or other energy supply uncertainties. The public utility, on the other hand, is exposed to these market-oriented risks. Utility investment in on-site solar can provide some diversification. This benefit must he folded in to the engineering economic return to estimate a final figure of merit in given circumstances. This report will outline a methodology for making these assessments in the case where utilities capitalize these investments, i.e. own the system, and where they simply finance them.

We will find that the financial risk of utility investment in onsite solar is low. The reason for this result is that such investments minimize the possibility of failure to realize the allowed rate of return. On site solar investment eliminates part of the utility's long run demand uncertainties that are presently exacerbated by investment in conventional long lead time technologies. Because on site solar comes in sma11 increments rather than huge blocks the timing of investment can follow demand and growth patterns. The potential default risk associated with on site solar does not appear to be correlated with macro-economic movements, so there should be no risk penalty from this factor.

This low risk property of utility investment in on site solar can be captured either under capitalization (i.e. rate-basing) or under a financing option. The major financial difference between these approaches is the role of taxation. The importance of this 
factor depends strongly on the applicability of capital investment jncentives such as accelerated depreciation and investment credits.

Our main conclusion is that the low financial risks for these schemes means that low cost capital should be available for utility investment in on-site solar. Numerous local regulatory policies will affect the precise implementation of either capitalization or financing. These are best taken up at the case study level. Nonetheless our generic analysis suggests that the financial viability of on site solar investment is greater than that associated with investment in conventional technology whose financial risks are greater.

\subsection{Outline of the Analysis}

The discussion will be organized in the following sequence. Section 2 will summarize the major features of the CAPM including a survey of those applications which are most relevant to our analysis. These include utility return on equity calculations and project evaluation techniques. In section 3 we will discuss how to apply empirical results based on CAPM methods. In particular we will distinguish applications to the capitalization variant of the utility investment strategy and the financing variant. Subsidization rationales will also be discussed. Section 4 will summarize empirical results to date, including estimation problems for the various risk measures. Finally in section 5 we will review the general problem of financial risk assessment forenergy technologies.

\subsection{The Capita1 Asset Pricing Mode1}

\subsection{Definitions and Examples}

The Capital Asset Pricing Model (CAPM) is based on an economic theory of capital market behavior which establishes a formal representation of the trade-off between the risk and return of investments. 
There are several textbook expositions of the economic assumptions and formal framework underlying this model (see ref. 2,3). For our purposes, however, it is sufficient to discuss the model's two basic parameters and their essential relations. CAPM assumes that all investments can be thought of as random variables characterized by an expected value of the return and some variance. The variance of the return is identified as the risk of the investment.

The first major construction of the theory is the capital market line (CML) which is shown in Figure 1. The curve $A B$ is the efficient frontier of the set of teasible portfolios consisting of risky assets. This is simply the locus of points in the space of risk and returns which gives the maximum return for given risk or alternatively the minimum risk for a given return. The capital market line is constructed by adding to the universe of risky securities a risk-free security with return $R_{f}$. The CML is a new kind of efficient frontier describing a world in which the best you can do in terms of risk and return is to construct a portfolio which is a linear combination of the risk-free asset and the market portfolio M. The proof of this result shows that the CML is that tangent to the curve $A B$ which goes through the risk-free rate of return $R_{f}$. The risk free return, $R_{f}$, is usually thought of as the return on_short term Treasury bills. $R_{f}$ can change over time, of course, and therefore so will the capital market 1 ine.

The CAPM is derived from the CML by constructing a new portfolio $P$ which is a linear combination of a new asset $i$ and the market portfolio $M$. Then by essentially the same argument which led to the construction of the CML it follows that the partial derivative of the return on the portfolio $\mathrm{p}, \mathrm{R}_{\mathrm{p}}$ with respect to the risk of the portfolio $\sigma_{p}$ must be the same as the slope of the CML. Analytically we have therefore

$$
\frac{\partial R_{p}}{\partial \sigma_{p}}=\frac{R_{m}-R_{f}}{\sigma_{m}}
$$


Figure 1

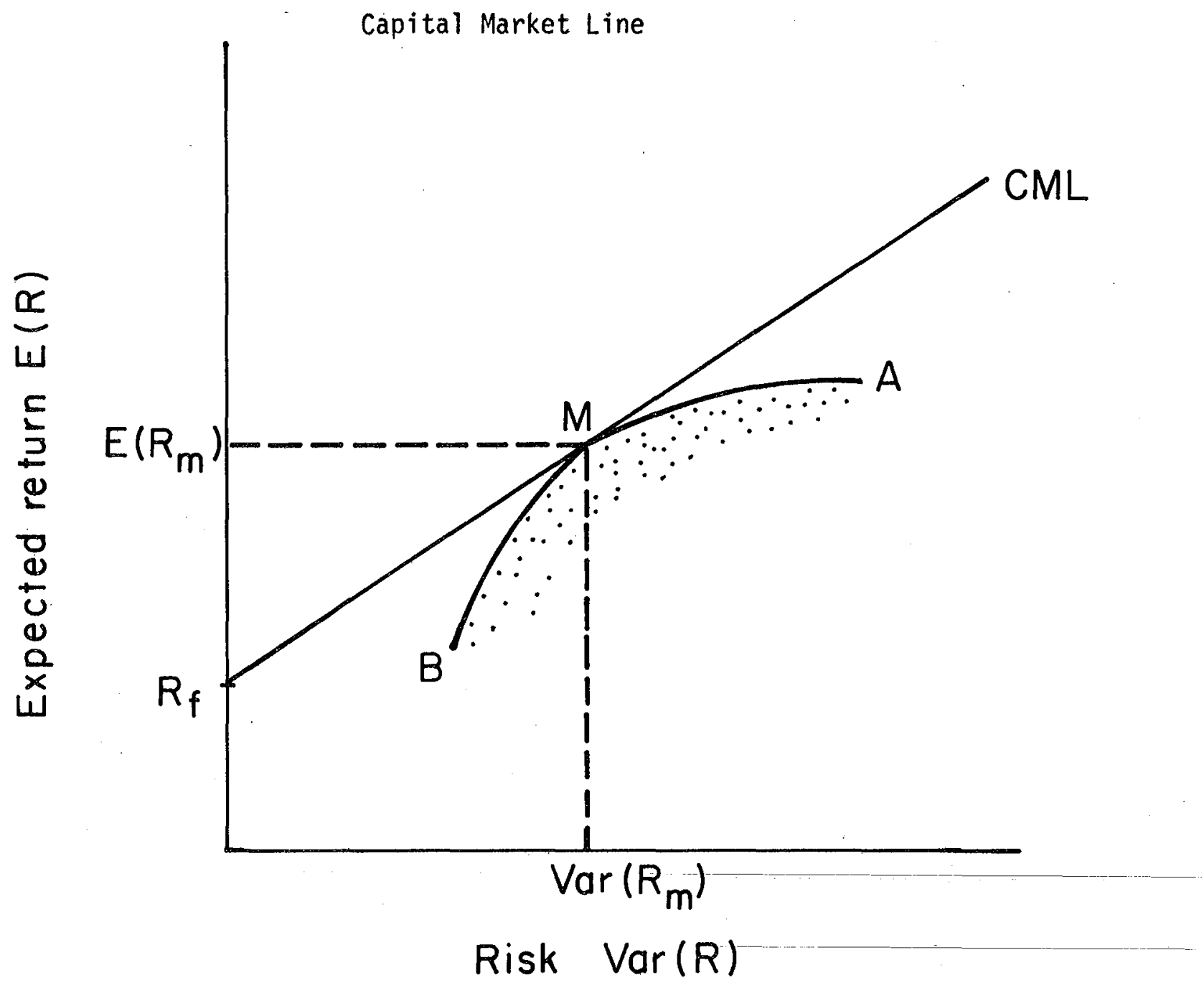

$X B L 789-2683$ 
Algebraically, equation (1) can be transformed into the following valuation formula for the risky security $i$ :

$$
E\left(R_{i}\right)=R_{f}+\beta_{i}\left[E\left(R_{m}\right)-R_{f}\right]
$$

where

$$
\beta_{i}=\frac{\operatorname{Cov}\left(R_{i}, R_{m}\right)}{\operatorname{Var}\left(R_{m}\right)}
$$

The derivation of equations (2) and (3) from (1) is given in Appendix 1.

\begin{tabular}{|c|c|c|c|c|}
\hline $\begin{array}{l}\text { Expected Return on } \\
\text { Risky Security i }\end{array}$ & $=$ & $\begin{array}{l}\text { Risk-free } \\
\text { Rate }\end{array}$ & + & $\begin{array}{l}\text { Risk Premium which is pro- } \\
\text { portional to the "vola- } \\
\text { tility" of the security } \\
\text { and the market price of risk }\end{array}$ \\
\hline
\end{tabular}
What these equations are saying can be expressed as follows:

The second term on the right-hand side of (2) is the risk premium for security $i$. It consists of two components, a parameter $\beta_{i}$ of the asset $i$ which is called the "volatility" of the asset's return, and the "market price of risk." The latter concept is quite straightforward. It simply says that the market portfolio will give a return of $\mathrm{E}\left(\mathrm{R}_{\mathrm{m}}\right)-\mathrm{R}_{f}$ to compensate investors for the total risk being accepted. For an asset $i$ with $\beta_{i}=1$, equation (2) shows that $E\left(R_{i}\right)=E\left(R_{m}\right)$; that is, the return is the same as the market return. Equation (3) says this in the language of probability, namely that the return on asset $i$ co-varies exactly with the market return. The parameter $\beta_{i}$ measures the sensitivity of $R_{i}$ to market fluctuations. A volatile asset, $\beta>1$, fluctuates more extremely than the market. A "growth" stock is an example of such behavior. When the market is up, high beta stocks out-perform the indices; conversely when the market is down. An asset'with $\beta<1$ is less sensitive than the market to macroeconomic changes. Utility stocks are examples of securities with such low beta behavior. It is even possible to have assets with negative beta. These would be assets whose return fluctuated countex-cyclically with macroeconomic movements. Gold is usually cited as an example of such an asset. 


\subsection{The Historical Record}

CAPM would not be interesting unless there were evidence that it is a reasonable model of security valuation. Finding such evidence is complicated by the model's formulation in terms of investors expectations rather than in terms of realized returns. Nonetheless various historical studies of past security performance have shown that beta and returns are correlated in the way predicted by CAPM (a review of these studies is given in ref.4). It will be particularly useful, however, for our discussion of CAPM applications to pay some careful attention to differences between model predictions and empirical results.

In Figure 2 we summarize a common, but by no means universal, phenomenon resulting from tests of CAPM. In this graph we plot a theoretical security market line (SML) which is calculated from a version of equation (2) where expected values of return are replaced by average realized returns. We a1so plot an empirical or actual security market line which is simply fit to a set of points corresponding to security returns and estimated values of beta. If CAPM were exact, these two lines would be identica1. Figure 2 shows the situation in which the zero risk asset has a return below the intercept of the return-beta regression (actual SML), and the slope of the empirical line is less than what was predicted. It has also been found that at times the actual slope is greater than the theoretical slope. This phenomenon has led to various adjustment rules which will allow for correction of the "raw" or "technical" beta estimation. We will highlight a few of the more interesting results of this kind.

Estimates of beta over different time periods for a given security are likely to fluctuate with considerable scatter. The scatter of $\beta$ estimates is reduced if we group securities into industry related sets. Appendix 4 shows the greater degree of stability in the value of $\beta$ for the Standard and Poor's Utility 
Figure 2

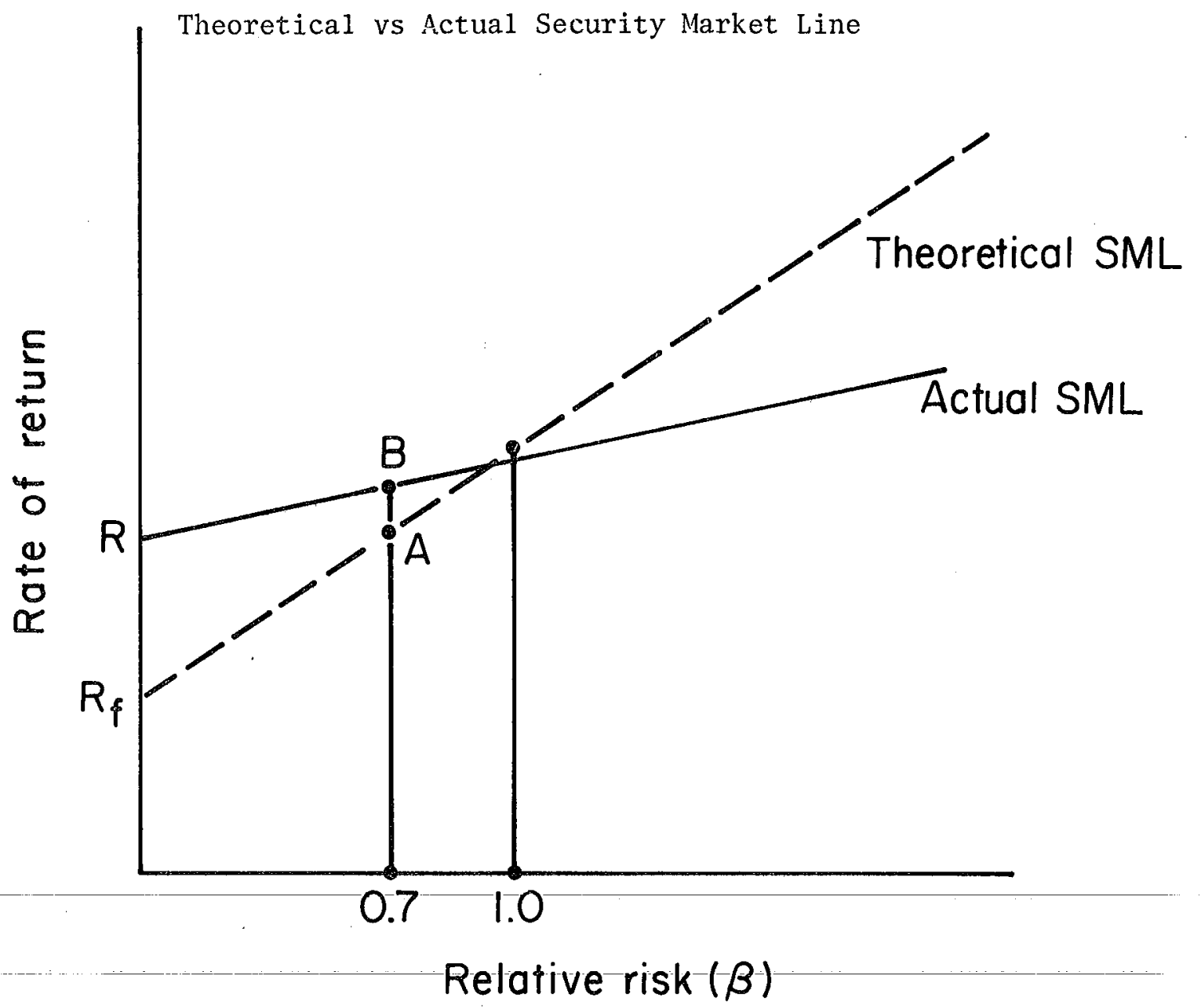

XBL 789-2682 
Index compared to one California utilities. Data such as this, which is discussed more fully in Appendix 4, has been used to motivate a whole host of rules to adjust the raw beta of an individual security for various CAPM applications. One simple form of adjustment is to treat the industry average as a norm and weight this with the technical results obtained for a given security. This approach is used by Merri11, Lynch, Pierce, Fenner and Smith, Inc. and Weils Fargo Bank (see ref. 5). Another technique is the use of certain current financial indicators of a firm such as variance of cash flow, current dividend yield and market capitalization to adjust individual security beta estimates (see ref 6). Consideration of these approaches to the empirical problems of applying CAPM is essential.

\subsection{Application to Utility Equity Returns.}

Because public utilities are regulated, the price of their securities is influenced by the non-market administrative decisions of the regulatory commission. However, the judicial principles on which regulation is based suggest that CAPM might be a useful tool for setting the allowed rate of return on equity capita1. This follows from the standard language on the criteria for determining the rate of return incorporated in the Hope decision:

The return to the equity owner should be commensurate with returns on investments and other enterprises having corresponding risks. That return, moreover, should be sufficient to assume confidence in the financial integrity of the enterprise so as to maintain its credit and attract capital (ref 7). CAPM is nothing but a methodology for determining the price of risk for equivalent securities.

In practice, however, the theory runs into the problem indicated by Figure 2. When CAPM is applied to utility stocks we have found that $B$ is consistently less than one. For $\beta$ sufficiently less than one CAPM might predict lower equity returns than the actual market 1 ine. In Figure 2 the distance between points $A$ and $B$ indicates the kind of underestimate in equity return that may result from straightforward 
use of CAPM. This empirical problem, coupled with the real-world implausibility of some of the CAPM postulates, has led some authors to reject this regulatory application of the model (see ref. 8).

This argument is particularly important for our subsequent discussion, because we will argue that on-site solar investment would be quite a low-risk, i.e., low beta, project for a utility. A logical conclusion from this line of thinking might be the following regulatory incentive paradox. Suppose a reluctant utility is persuaded by its regulators to capitalize on site solar investment. As a reward for this compliance, the regulators promptly lower the utility's allowed return on equity to correct for the reduced beta of the company as a result of the solar investment. This amounts to providing negative financial incentives for behavior ostensibly desired by the regulators.

Such a paradox results on $1 y$ when there is a confusion of time scales. Allowed returns on equity are decided on a time scale of one to two years. Energy project evaluation applications of CAPM methods are addressed to time scales of 10 to 30 years. The financial diversification benefit of utility investment in solar cannot be expected to show up instantly in market valuation or reduced security beta. These may-be-1ong-term-trends, but-their-magnitude-may-notbe noticeable within the error ranges of CAPM techniques. What can be estimated with greater reliability is the relative financial risks of competing technologies. It is on this subject that CAPM can provide useful discrimination because the range is large. We will take up this more general topic in section 5 . For now we must shift attention to the specific techniques for applying CAPM to project evaluation.

\subsection{Project Evaluation}

We would like to estimate the risk premium of a project as a function of the agent who undertakes it and the project's return characteristics. The investment decision from a purely financial 
point of view amounts to a test of whether the excess return of the project exceeds the risk premium. Following Mossin (ref.3), we can write this as

where

$$
\mu_{z}-r_{f} I_{z} \geq R b_{z},
$$

$$
\begin{aligned}
& \mu_{z}=\text { expected return on project } z \\
& r_{f}=\text { risk-free rate } \\
& I_{z}=\text { investment cost of } z \\
& R=\text { market price of risk } \\
& \mathrm{b}_{z}=\text { risk measure }
\end{aligned}
$$

The excess return is the difference between the expected return and the return on a risk-free asset $\left(\mu_{z}-r_{f}{ }_{z}\right)$.

To derive a general expression for the risk premium $\mathrm{Rb}_{\mathrm{z}}$, we again follow Mossin and break up the risk measure into the three terms which follow

$$
b_{z}=\operatorname{cov}(z, m)+\operatorname{cov}(z, J)+\operatorname{cov}(z, z)
$$

where

$$
\begin{aligned}
& m \text { is the market return (random variable) } \\
& z \text { is the return of project } z \text { (random variable with mean } \mu_{z} \text { ) } \\
& J \text { is the return on other projects of the firm } J \text {. }
\end{aligned}
$$

In Appendix 2 we show that for smal1 investments (compared to the size of the firm) equation (5) and (6) reduce to the following

$$
E\left(r_{z}\right)-r_{f} \geq\left[E\left(x_{m}\right)-r_{f}\right] \beta_{z}
$$

This expression is just CAPM scaled down to the project level. The key parameter is $B_{z}$. This is the co-variance of the project's rater: of return with the market rate of return divided by the variance of the market rate of return. It is a convenient feature of eq (7) that it is expressed in terms of rate of return, rather than in units of dollars. Equations (5) and (6) are expressed in gross dollar returns not percentage rates. 
Equation (7) has the important subtlety that it is not an invariant for al1 financial actors. The regulated utility will face a lower default risk in solar finance than other potential intermediaries. If someone refuses to pay his utility bill, he risks losing the essential energy services provided by the utility. Other financial actors do not have this leverage. This means thatwith regard to this factor $\beta$ be estimated from a more stable proxy for utility investment than would be reasonable in a different situation. The default risk is lower for utility bills than for finance company payments for example. Thus although we have eliminated the second term in eq. (6), the covariance of the project and the firm, from our estimate of the risk premium in eq. (7), we still must consider risk estimates to be a function of the actors involved.

For our purpose equation (7) can be used to determine the finance charge seen by the customer in the various utility finance or ownership schemes. Since equation (7) represents the risk premium for the investment, the finance charge can be set as follows:

$$
\text { Finance charge }=\text { Risk-free Rate }+ \text { Risk Premium (8) }
$$

Equation (8) represents a simple flow-through approach to the cost-of-capital question for utility investment in on-site solar. It says that the consumer will pay a rate of interest equal to the utility's threshold rate of return for accepting the investment. In ${ }^{-}$the ${ }^{-}$simplest-case-the-finance-charge-calculated from equation (3) will equal the expected rate of return from the engineering economics. Then there will be no additional complexities. In most cases these two will not be equal. Therefore we must study the regulatory and financial consequences of the case where the expected rate of return differs from the finance charge. This is taken up in Section 3.

\subsection{Regulatory Applications}

Regulated utilities are limited in the return they can earn on investment by that which the state or local jurisdiction allows. It has been argued that such rate of return regulation provides an incentive towards overcapitalization; inputs will not be used in optimal proportions. This is the famous Averch-Johnson Thesis that has been the subject of extensive discussion. (ref. 10, 11). This argument 
is discussed in the case of on-site solar in an accompanying analysis (ref ). For our purposes it will be sufficient to discuss the various regulatory options available to State Commissions that can adjust realized returns with expected returns. Before turning to this subject we must spend some time analyzing the rate of return calculation in our current context.

\subsection{Rate of Return Calculations}

In principle it is straight forward to calculate the rate of return. We assume that the appropriate measure is the internal rate of return that is found by using the discounted cash flow (DCF) method. We will write down a simple version of this basic problem. To find internal role of return, solve for $x$ in equation (9):

$$
C=R_{0} \sum_{i=1}^{n} \cdot\left(\frac{1+r}{1+x}\right)^{i},
$$

where

$$
\begin{aligned}
& \mathrm{C}=\text { capital cost }(\$) \\
& \mathrm{n}=\text { iife-time } \\
& \mathrm{r}=\text { escalation rate of energy prices }(\%) \\
& \mathrm{R}_{\mathrm{O}}=\text { return (benefit) in first year }(\$)
\end{aligned}
$$

One difficulty in using the method stems from uncertainty concerning the escalation rate in energy prices. More fundamental is the problem of assigning a value to the conventional energy displaced by the on-site solar system. This is really just the marginal cost problem. The first year's return, $R_{O}$, is the product of some units of energy displaced times a price per unit. The difficult practical problem is to decide which price truly represents the margin. There is considerable controversy on this problem (see ref. 12). The main ambiguity involved is the question of identifying "displaced" supply costs. On-site solar wi11 reduce utility energy (kwh) requirements immediately and thereby produce fuel cost savings (short-run marginal costs). In the long run some capacity (kw) costs may be saved. These can be difficult to identify. 
Techniques are available to estimate this in particular situations (see ref 13), but the question ca11s for detailed case study.

For our purposes it is sufficient to get a first-order approximation. We will make estimates by using the customer's cost of electricity as the value of energy saved and escalate this with an expected rate of increase in oil prices. The latter is an appropriate escalator for oil-based utility systems such as those in California. The benefit stream must also be modified by expenses for maintenance. In Table 1 below we perform some sample calculations for California's conditions. 'l'hese results show that the rate of return on solar hot water heating can vary widely. If we were to examine active space heating systems in the same way the return could be expected to be lower in general (ref. 14).

There are other corrections to the rate of return calculation that may also need to be made. Several studies have found that electric backup for on-site solar may cost more on the margin than electricity supplied for other technologies providing thermal end uses (ref. 1, 32) Such results are very dependent on solar system configuration and climate. Since this phenomenon is essentially a cost and not a financial risk, it can best be treated as a deduction from the benefit stream. The back-up cost may a1so be transferred to other or a11 ratepayers by regulatory decision. There are examples of such transfers of cost in the area of utility insulation finance (see discussion of Consolidated Edison Program in ref. 15).

Finally we must consider the question of on-site solar system reliability. The important distinction to be made here is again the difference between a cost and a risk. If a certain fraction, say $10 \%$, of the solar systems which a utility has invested in are not functioning for one reason or another, then the average rate of return will be reduced by $10 \%$. Although reliability problems will cause variation in the cash flow associated with these investments, it is a random not a systematic variation. Therefore it is excluded from our estimates of beta and shows up on the return calculation as decreased revenue. 
Now we have identified all the components of the return calculation except for taxes. We will defer the discussion of taxation to our treatment of the utility ownership or capitalization alternative. First we will discuss the conceptually simpler alternative of utility finance.

\subsection{The Financing Option}

Let us consider the case in which the regulatory commission limits the utility to the role of financing agent for on-site solar. From the consumer's point of view the utility is providing a financial economy of scale by reducing the risk premium on the investment. In sectin 4 we will present arguments supporting the proposition that the beta for these projects is low; our first approximation is 0.15 for the cases considered. Using equations (7) and (8) we can translate this into a finance charge. We need two estimates to make this calculation. The first is the appropr. ate risk-free rate. The second is the market price of risk, $E\left(r_{m}\right)-r_{f}$. For the sake of illustration we will rely on the values estimated by Prof. Whitcomb in a recent regulatory proceeding (ref. 9). Using a long term aver-age for the market price of risk, he estimates its value at $8.86 \%$. For the risk free rate, Whitcomb estimates $7.0 \%$. Now we make our finance charge calculation;

$$
\text { Finance Charge }=7.0+0.15(8.82)=8.41 \%
$$

This rate is low. It is below the first mortgage interest rate faced by most consumers and well below expected rates from other financing alternatives available to consumers. These include second mortgages or home improvement 1oans.

It remains to be determined, of course, whether the regulatory commission will adopt the finance charge estimated in this way or some other figure. In the most analogous situation, the utility finance of insulation, actual finance charges vary from $6.5 \%$ to $14 \%$ (see ref. 15). The extreme values represent either a public 
Table 1: Interna1 Rate of Return as a Function of Region, System Lifetime and Taxation

Assumptions Solar Hot Water Heater Capita1 Cost $=\$ 1500$ (ref. 29)

Annual Maintenance Expenses $\quad=\$ 60 / y r . \quad($ ref. 29)

Energy Price Escalation Rate $\quad=5.1 \%$ (real dollars)/yr. (ref. 30)

Inflation Rate $\quad=5 \% / \mathrm{yr}$.

Regional Performance and Value (Energy Displaced and 1978 cost per unit)

San Diego: $4800 \mathrm{kwh}, 4.8 \$ / \mathrm{kwh}$ (ref. 29)

Northern California: $2800 \mathrm{kwh}, 4.0 \% / \mathrm{kwh}$ (ref. 31)

Internal Rate of Return

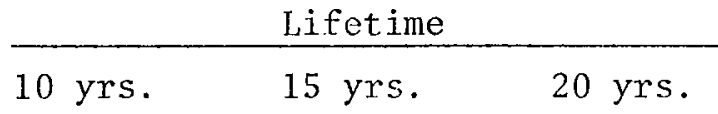

Case 1.

No Federal Tax

$\begin{array}{lcrr}\text { San Diego } & 14.5 \% & 20.0 \% & 22.3 \% \\ \text { Northern California } & 0 & 6.0 \% & 10.0 \%\end{array}$

Case 2.

$48 \%$ Federal Tax

San Diego

$8.8 \%$

$13.3 \%$

$15.3 \%$

Northern California

0

$3.8 \%$

$6.8 \%$

Case 3 .

$55 \%$ State Tax Credit

33\% Personal Income Tax

$\begin{array}{lrrr}\text { San Diego } & 25.5 \% & 29.5 \% & 30.8 \% \\ \text { Northern Ca1ifornia } & 3.5 \% & 11.5 \% & 15.0 \%\end{array}$

Note: California grants a 55\% state income tax credit for solar. This benefit, however, also shows up as a reduced deduction for federal tax purposes. The cost of the reduced deduction is the dollar magnitude of the state solar tax credit times the marginal federal tax rate. These joint impacts can be expressed as a reduction to an "effective" state tax credit by the formula.

Effective Tax Credit $=$ Nominal Credit - Marginal IRS Rate $\mathrm{x}$ Nominal Credit 
policy commitment to the program (the low or subsidized rate) or a profit making approach (the high rate). The value of the CAPM method for estimating the financial risk of on-site solar investments is that it creates a yardstick for policy decision. If a regulatory commission wants to subsidize solar investment it will set a rate below the CAPM estimate. Conversely if the decision is to treat this activity as another profit center. The important point is that degrees of consumer subsidization or utility incentivization can be measured.

From the consumer side, a rational decision to invest in on site solar would be indicated if the expected return exceeded the finance charge. This would mean that in terms of cash payments the sum of the utility bill plus solar payment would be less than or equal to the previous utility bill, i.e. without solar. The analysis of the consumer's position would also have to take tax incentives into account. California already has a tax credit for solar investment and federal action in this area is being considered. These effects will improve the consumers rate of return on the solar projects, but would not change the finance charge. See Table 1 for examples.

Finally there are a number of problems surrounding the actual design of a financing programs. We will only indicate a few-of these. Separate accounts must be created for financing programs. Regulators must decide how much freedom the utility wil1: have with the cash flows generated. Will the funds received be treated as income for the purpose of calculating the interest coverage ratios? How much of each payment will be credited to interest and how much to principal? If a subsidy program is chosen, how will the extra costs be allocated? These problems get us into the policies specific to one commission or another. Therefore they are best treated on the case study level where detailed variants can be examined.

\subsection{The Capitalization Option}

When we turn our consideration to the ownership or capitalization alternative, we can no longer ignore the role of taxation. Qualitively 
it is clear that the after-tax rate of return from on site solar will be less than the before tax return that is associated with the financing option. To quantify the effect we must adjust the cash flow in year $i$ to reflect the reduced net benefit. Considering only federal taxes for the moment, we re-write the ith term in the DCF equation (9) as follows:

$$
\begin{aligned}
\text { Cash Flow }= & \text { Revenue }- \text { Expenses } \\
\text { We express Taxes }= & \tau\left[\operatorname{Rev}_{i}-\text { Ex }_{i}-\text { Dep }_{i}\right], \\
\text { where } \tau= & \text { federal tax rate; } \operatorname{Jep}_{i}=\text { depreciation } \\
& \text { allowed in year } i .
\end{aligned}
$$

Substituting (11) into (10) we get Cash Flow

$$
=(1-\tau)\left[\operatorname{Rev}_{i}-\mathrm{Ex}_{i}\right]+\tau \operatorname{Dep}_{i}
$$

In Table 1 we show the effect of taxation on the rate of return assuming straight-line depreciation and $48 \%$ tax rate. These results would improve if we used capital incentives such as investment tax credit and accelerated depreciation. However, there is some question about the applicability of these incentives to on-site solar investment (16) If applicab1e, however, the rate of return could increase by $50 \%$.

From-a practical-point of view-it-would-be-more difficult to make the rate of return calculation in this case because of the marginal cost problem. This difficulty is academic in a sense, because regulation will set the rate of return for this investment at the rate earned by any capital in the utility's rate base. The analogue of the subsidy and incentive problem discussed for financing is now seen in comparing the risk adjusted finance charge estimated from CAPM with the return on rate base.

If the return on rate base exceeds the risk adjusted finance charge, the utility is making a profit. The regulator can then choose to allow this as an incentive, or reduce the excess return by making an annualized adjustment to total revenue requirements. This is a policy choice, but is not without economic consequences. Allowing the financial incentive should be reflected in higher prices for utility equity and therefore a reduced capital burden on rate payers. This can be compared to the benefit rate payers receive from the reduced revenue requirements associated with denying the financial incentive. Quantification of these trade-offs will depend on particular circumstances and are best estimated by individual case studies. 
It might also happen that the return on rate base is less than the risk adjusted finance charge. In this case the solar investment would require a subsidy from other ratepayers to avoid further deterioration of the utility's financial position. It is unlikely that the magnitude of differences in this case would be persist because the solar beta is going to be less than the beta of the utility's stock. Therefore the cost of capital for the solar investment will be less than the cost of capita1 for the "average" utility investment. In the short-run the realized rate of return on rate base may be low because of regulatory lags, interest rate changes and so on. In the long run the return on rate base will exceed the risk adjusted finance charge for on site solar. This is true because currently planned projects are typically higher beta propositions than solar. This latter point will be pursued in greater detail in Section 5. The reasons for this will begin to emerge in our discussion of the factors which do and do not contribute to the solax beta. This discussion appears in Section 4.

Despite the emphasis in this discussion on the regulatory rather than the engineering-economic aspect of the return, regulators cannot ignore the latter. A policy which mandates investment in uneconomic projects can only be justified by extraordinarily important social or political goals. In the variety of on site solar technologies, some have high returns, some have low or negative returns. A useful contrast is the passive approach to space conditioning compared to active systems. The former has relatively low incremental costs because it involves design concepts and margina1 additions of material. Active systems involve considerable hardware: collectors, pumps, storage tanks, etc. It is easy to understand how a utility might own active systems. The engineering economics of such systems can be poor (ref. 14). Passive systems promise better economics, but it is not clear how a utility can own anything in this case. This example suggest that there is no simple set of rules which will promise the optimal policy in all cases. Whether capitalization or utility finance will make sense in a given situation will depend on both regulatory policy and the nature of the project involved.

\subsection{Empirica1 Results}

In this section we will discuss empirical issues associated with applying CAPM methods to the utility solar investment problem. The discussion 
will be divided in two parts. First we discuss the validity of CAPM in explaining the returns on utility stocks. We will examine both aggregate industry behavior and individual firms. Second we will discuss the process used to estimate the beta for utility solar investment.

\subsection{CAPM Applied to Utility Securities}

There are two equations which can be used to estimate security betas. The first method is a straightforward application of equation (2) expressed in rates of return rather than monetary returns and replacing expected values with realized values. We write this version as follows:

$$
\left(r_{i}-r_{f}\right)=\beta_{i}\left(r_{m}-r_{f}\right)+\alpha_{i},
$$

where

$$
\begin{aligned}
& r_{i}=\text { rate of return on security } i \\
& r_{f}=\text { risk-free rate of return } \\
& r_{m}=\text { return of the market } \\
& \beta_{i}=\text { volatility of security } i \\
& \alpha_{i}=\text { constant to be estimated. }
\end{aligned}
$$

Equation (13) can be estimated by forcing $\alpha_{i}$ to be zero and calculating beta.

Another formulation of CAPM is the Sharpe single index mode1 (ref. 2). This resembles eq. (13) except for the role of the risk-free rate. To estimate beta-in this formulation-we-consider the-following-equation:

$$
r_{i}=\beta_{i}^{\prime} r_{m}+\frac{1}{\alpha_{i}}
$$

The parameter $\alpha_{i}^{\prime}$ in this equation should be the risk-free rate, $r_{f}$. In Appendix 3 we show that while we occasionally get the result $\alpha_{i}^{\prime}>r_{f}$, which is the situation pictured in Figure $2, \alpha_{i}^{\prime}$ is in fact not significantly different than $r_{f}$. We could also compare the estimates of beta from eqs. (13) and (14). If we found that $\beta_{i}=\beta_{i}^{\prime}$, this would show that beta is independent of which method is used to estimate it, or alternatively that the risk-free rate is not correlated with the market.

In Section 2.2 we mentioned the effect of periodization of the scatter of points underlying an estimate of security betas. In Appendix 4 we show how lengthening the periodover which $\beta$ is estimated improves the rit of model to data for the utility index and the individual securities. There is a trade-off in the choice of interval between improved statis- 
tical reliability and loss of information concerning the true range of scatter. This phenomenon is the most difficult to overcome in a practical sense if CAPM were to be applied, for example, as the sole determinant of utility equity returns.

\subsection{Estimating Beta for Utility Investment in On-Site Solar}

There are actually two approaches to estimating beta. The most conventional method is the use of historical data in a regression equation. This is the approach used in Sec. 4.1 and documented in Appendix 3. An alternative approach has been outlined by Rosenberg and Guy (ref. 17) which proceeds from an analysis of the degree of uncertainty of economic events and the response of security returns to these events. This 1atter approach has conceptual appeal but is difficult to use in practice. For our purposes it will turn out that ordinary regression methods will be suitable to estimate beta for utility investment in on-site solar. To make this argument plausible we will include in our analysis a discussion of the fundamental causes of risk in the utility industry. Wethen proceed to apply this inventory of risk to the case at hand, after accounting for special characteristics of the on-site solar investment.

\subsubsection{Default Risk}

On-site solar investments will impose a default risk on the utility which invests in them or finances them. The default risk, i.e., the risk that someone will not make the monthly payment for the system, can be divided into two components, the vacancy rate and the uncollectible rate. If a house with such a system is empty, no one is amortizing the capital investment. If the house is occupied, there is a chance that the bill will not be paid, i.e, it is uncollectible. Of these two effects, it is the vacancy rate which is larger. For example, data collected by Electrica1 World shows that in the Western states the uncollectible rate went from just over $0.2 \%$ in 1970 to just under $0.3 \%$ in 1975 (ref. 18). By contrast, the vacancy rate for multi-unit residential buildings in the West has ranges from 4 to $8 \%$ (see Appendix 5). Since the magnitude of the uncollectible rate and 
its variation is less than the vacancy rate we can neglect the former until we have estimated beta for the latter effect.

We look for the co-variance of default risk with the market by estimating the following equation:

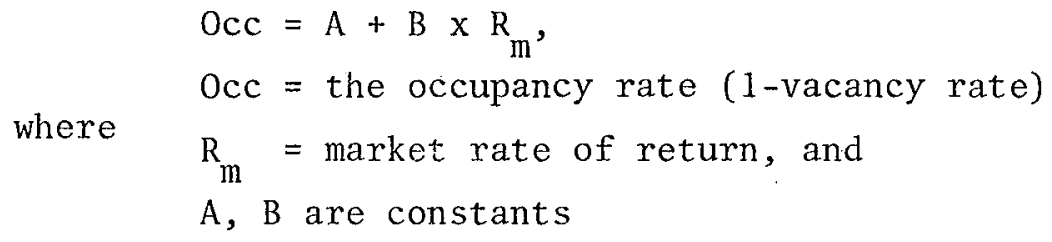

In Appendix 5 we show that $B$ is not significantly different than zero. This means we can also ignore the uncollectibles because its range of variation is less than the vacancy rate. Although these results do not demonstrate that there is no default risk, they do show that the market related component of the default risk can be neglected. This is the only part of the risk which matters in the CAPM. The default risk is the only additional risk burden that distinguishes on-site solar systems from other utility investments. It remains to determine the magnitude of other typical risks of utility investment as they apply to on-site solar.

\subsubsection{Conventional Utility Risks}

Regulated utilities face three basic kinds of financial risk. The first is essentially political; it is the risk that the regulators will not pass costs through to the customers because raising energy prices is unpopular. The second risk is administrative; it is the lag between the occurrence of costs and their incorporation in rates. In a period of increasing average costs the utility must wait to recover its expenses until its application for increases is processed. The phenomenon of regulatory lag is a short run incentive for efficiency, provided the gap does not grow too large (see ref. 11). The third category of risk is that the market will not realize the rate of return allowed by the regulator. This last category is the one which will concern us since it is directly relevant to CAPM analysis. Indeed utilities today are 
having just this kind of difficulty. Rates of return are not reaching authorized levels, and as a result utility equity is selling below book value. We shall examine these market risks in some detail.

A recent summary of the market related uncertainties and risks in the electric utility industry today is given by the Policy Overview of the California Energy Commission's Biennial Report (ref. 20). The following list of factors highlights the major problems:

(A) Demand Uncertainty - the impact of highex prices, voluntary and mandatory conservation means that future demand is difficult to determine.

(B) Changes in Energy Costs - the prices of fuels and conversion technologies are uncertain and unpredictable,

(C) Long Lead Time Projects - large supply projects take years to complete, have uncertain costs and completion dates and tie up large amounis of capital for years before earning a return.

While this list is by no means exhaustive it does include the major generic risks of the energy supply industry. Moreover, the problems tend to interact with one another. Long lead time-projects-are-riskier when the uncertainty of demand is increasing. A long lead time technology is more vulnerable to changes in factor costs than a short lead time system.

On-site solar systems eliminate much of the risk associated with (A) - (C). Because it is matched to end-use demand, there is no uncertainty associated. with a long term forecast of future requirements. The demand for hot water and space heat is inelastic compared to other energy requirements. The lead time for on-site solar is short, on the order of months rather than years. Thus, the utility can adjust its solar investment program to match the variation in population growth and new housing construction. It does not have to accept the risk of building large projects over many years with the expectation (or hope) that demand will justify the investment. In the present climate of rapidly rising energy costs, utilities must face the prospect that large commercial or industrial customers may choose to satisfy their energy requirements 
independently. Utility involvement in on site solar investment will reduce some of this risk. Finally there is no cost escalation risk associated with solar conversion. Cartels cannot manipulate the price of fuel.

These arguments do not mean that there is no risk at all. On-site solar is a long term investment and bears the interest rate risk that al1 such investments face. Electrical utilities face an interest rate risk that is typically greater than other industries (see ref.21). This is really just the corollary of the finding that utilities are low beta industry compared to the market as a whole. If security prices are less sensitive to market fluctuations, they will be more sensitive to interest rate fluctuations. The market risk of on-site solar then is comparable to the market risk of any other 1ong term investment such as high-grade corporate bends. We estimate the following equation

$$
\begin{aligned}
\text { BROR }= & \alpha_{1}+\beta_{1} r_{m}, \\
\text { Where } \quad= & \text { rate of return on Standard and Poor's } \\
& \text { high-grade corporate bond index } \\
r_{m}= & \text { market rate of return } \\
\alpha_{1}= & \text { constant } \\
\beta_{1}= & \frac{\text { Cov }\left(B R O R, r_{m}\right) .}{\operatorname{var}\left(r_{m}\right)}
\end{aligned}
$$

The results of this regression are shown in Figure A8 The parameter $\beta_{1}$ is the slope of the fitted line and has the value 0.15. Detailed results are collected in Appendix 5.

The conclusion of this discussion is that beta for utility investment in on-site solar appears to be low. The market related financial risk is small for the data we have examined. Our results, however, are contingent on the validity and generalizability of the methods. Moreover, the possibility remains that market related default risk may be non-zero in particular cases. We have relied upon aggregated data for one region that may be misleading. 
If this factor turns out to be significant in a given market, there are important methodological consequences. Use of our single proxy for the solar beta then becomes untenable. What is worse, we will have to construct a model for aggregating various effects into a single aggregate measure, the project beta. This problem brings us back to consideration of the underlying determinants of beta, the uncertainty of economic events and their impact on particular assets. We will outline the features of this problem in Section 5. But before turning to that discussion we will complete our analysis of the on-site solar financial risk by comparing our results with data that indicates the financial risk of conventional technologies.

\subsubsection{Preliminary Comparisons}

The argument up to now may be summarized as follows. Utility companies are low beta assets. The California utilities we have studied vary from $\beta=0.56$ to $\beta=0.67$. The Standard and Poor Utility Index is closer to $\beta=0.91$. Utility investment in on-site solar we have estimated would reduce the average cost of capital; beta for this investment being around 0.15 . It remains to argue that conventional projects now being planned have financial risks that are considerably greater than the historical average. If this is true, then the diversifying effect of utility investment in on-site solar is even greater than what appears by looking at historical beta alone. We will begin to argue that conventional projects on the margin are high beta propositions by examining the implications of increased rates of return on equity for one of the California utilities we have studied.

In Section 3.2 we made a numerical estimate of the finance charge for utility investment in on-site solar using estimated values of CAPM parameters due to Whitcomb (ref. 9). We will use these parameter values to check whether our estimate of Pacific Gas and Electric Company beta is consistent with their allowed return on equity. The beta implied by CAPM, Whitcomb's estimated parameters and the allowed return on equity is calculated as follows:

Allowed Return on Equity $=$ Risk-free Rate $+\beta$ (Market Price of Risk)

Substituting into (16), we get $12.83=7.0+\beta(8.82)$

$$
\beta=.66
$$


This compares to our estimate of $\beta=0.56$. The agreement is reasonable, but not perfect. The value of return on equity is the latest approved value (ref. 22).

For illustrative purposes we consider PGGE's requested return on equity of $15.0 \%$ (ref. 23). This is associated with the financing requirements of a resource plan going out to 1996. Substituting this value into eq. (16) with everything else fixed, we find that $\beta=0.91$. It is instructive to decompose this new beta into an historical and a marginal component to determine the risk of the new investments. To do this we need a capitalization weighting of the historical and marginal components. This means we need to know the number of new equity shares needed to finance theplan. One estimate of this has been made by W.R.Z. Willey (ref. 24) on the assumption that shares sell at $115 \%$ of book value. He estimates that new equity will represent $56 \%$ of existing equity by 1996 under this plan. We can can calculate the marginal beta of $\mathrm{PG} \& \mathrm{gE}$ (or the beta of its resuurce plan) as follows:

Capital Weight (Historical $\beta)+$ Capital Weight (Marginal $\beta)=$ Tota1 Capita1 $(\beta=0.91)$

Substituting into (17) we get

$1.0(.66)+.56($ Margina1 $\beta)=1.56(0.91)$

Marginal $\beta=1.36$.

This result, whose numerical precision is limited, demonstrates qualitatively that the financial risks of current1y planned conventional technology is higher than historical levels. In comparison with on-site solar investment the deviation from historical levels of risk is about as great on the high side for conventional technology as solar is on the low side. We will pursue this theme in the following section where we take up consideration of the underlying determinants of risk for energy technology projects.

\subsection{Determinants of Asset Betas}

There is only a limited literature which is relevant to determining the incidence of financial risk and differential capital charges for energy technologies. General accounts of project valuation problem are typically so 
abstracted from the particularities of energy investment that they do not offer a practical guide to the problem. On the other extreme there is an anecdotal 1iterature on comparitive capital charges from which examples and some principles may be drawn. We will take these two strands up separately.

\subsection{Elasticity of Expectations Mode1}

Myers and Turnbul1 (ref. 25) have recent1y extended the multi-period version of CAPM to a model of asset valuation in which expectations are periodically revised in the light of new information. These revisions are modelled as a set of weights which are attached to the historical stream of cash flows which the asset generated in the past. If the last period is given al1 the weight in formulating the expected casi flow for the next period, then the asset is said to have an elasticity of expectations equal to one. Conversely, if the last period has zero weight in forecasting expected cash flow for the subsequent period, then expectations are inelastic.

The authors then proceed to derive asset valuation formulas which express beta in terms of the familiar CAPM parameters. Indeed their formula may be seen as another "raw" beta adjustment technique which is more tailored to project valuation than to security valuation. In equation (18) below we write the expression for beta when asset life is infinite. The authors have produced a table of values which gives explicit numerical results for fixed pararieters and varying asset life. The table shows that eq. (18) is a reasonable first approximation for the lifetimes expected of energy projects.

$$
\begin{aligned}
\beta_{z, \text { adjusted }} & =\left(r_{f}+\nu\right) /\left(1-(M P R) \operatorname{cov}\left(r_{z}, r_{m}\right)\right)\left[\beta_{z, r a w}\right] \\
\text { where } r_{f} & =\text { risk-free rate } \\
\nu & =\text { elasticity of expectations }(0 \leq \nu \leqq 1) \\
M P R & =\text { market price of risk }\left(E\left(r_{m}\right)-r_{f}\right) \\
r_{z} & =\text { rate of return on asset } z \\
r_{m} & =\text { rate of return on the market. }
\end{aligned}
$$

The denominator in eq. (18) is typically a number less than one. So the adjustment to the raw beta measures the extent to which one can expect "surprises" in the cash flow generated by project $z$. Where the parameter $v$ is large, i.e. heavy weight is given to experience of the recent past, we 
must have revised initial expectations, i.e. discounted them. In this case the adjustment to the raw beta will tend to be a factor near to or greater than one. Conversely, where no surprises are expected, where initial expectations form a firm basis for the forecast of future cash flows, the adjustment will reduce the raw beta. In the limit a "certain" situation will reduce the raw beta by a factor equal to $r_{f}$, the risk-free rate of return. While equation (18) is suggestive, it really only translates risk adjustment from one set of conceptual categories to another. The elasticity of expectations is difficult to measure, perhaps impossible to forecast. If we can know it at a11, it is on $1 y$ in retrospect and rather qualitatively at that. That is, we can judge relative elasticities perhaps, but not absolute magnitudes. Nonetheless, the Myers-Turnbull language does suggest a way to interpret some data on the difference in capital charges associated with coal versus nuclear electric generation investments. It is to this more particular discussion that we now turn.

\subsection{Coal vs. Nuclear: An Example of Capital Charge Differentials}

In regulatory practice, technologies are differentiated by capital charge rates. Only certain contributing factors are commonly distinguished, however, and there is no uniform approach. For illustrative purposes we will reproduce data in Table 2 below which shows one recent and detailed comparison of the capital charges ${ }^{-}$associated ${ }^{-}$with $^{-}$coal $^{-}$and $^{-}$nuclear generation projects. of the utility risks 1isted in Section 4.2.2, on 1 y the lead time risk is included explicitly in Table 2, where it is represented by the Construction Compound Interest Factor (CCIF). In some versions of these calculations, CCIF is treated as part of the present value of the capital investment (ref. 27). Annua1 carrying charges then include only the components of return, depreciation and taxes. Even here, however, we see differences between coal and nuclear in Table 2. Our problem is to construct an account of these differences that is more general than anecdotal.

The Myers and Turnbull framework offers one possible line of argument. The reasons cited in Table 2 for the higher carrying charges associated with nuclear investments can be interpreted as evidence of revised expectations. The higher depreciation charges associated with nuclear decommissioning costs 
are expressed in accounting language as a negative net salvage value (ref. 26). It is doubtful if this component of cost was part of the original set of cost expectations used in initial estimates of the cost of nuclear power. The very term "negative net salvage value" is of recent vintage. Similarly the distinguished "financial risk" penalty of the nuclear investment can be understood as a change of expectations. Compared to coal combustion technology, nuclear can be seen as having more "surprises". As usual with this framework, "more" and "less" is hard to measure, especially to the precision of $0.2 \%$ differences in required return.

\subsection{The Lemon Technology Problem}

Up to now we have neglected the risk that on site solar systems will turn out to be inadequate on technical or engineering grounds. We can call this the risk of investing in a lemon technology. This risk applies to all technologies, of course, and is fundarnentally just another aspect of our limited knowledge. We only discover that we have invested in a lemon after the fact. In the Myers and Turnbull language we adjust our expectations on the basis of new information. 'The critical parameter in this framework, the elasticity of expectations, measures among other things when we learn the bad news. The sooner the ill tidings arrive, the lower is this elasticity, and hence the lower the beta of the assets in question. This brings us back to the lead time risk which we discussed in sec. 4.2.2. A long lead time technology is one in which potential bad news is delayed. If the amount of capital committed to such projects is large the total risk to the firm goes up accordingly. Here again the small incremental nature of on site solar turns out to be an advantage compared to the large scale, long lead time technologies.

\subsection{An Alternate Approach}

A potentially more explanatory quantitive approach to assessing the underlying determinants of energy project risk premiums lies in a possible variant in the CAPM framework. By adapting CAPM we have in effect assumed that nonmarket related risk, sometimes called un-systematic or residual risk, is unimportant for project valuation. Project cash flow variances that are not market correlated show up in the rate of return. While this procedure 
does relate market to non narket risk, the linkage is less clear and explicit than it might be. Indeed, many of the risks faced by a utility may not be systematic in the sense of CAPM. This possibility nay be even more plausible for the marginal investment. For example, cn site solar investment is vulnerable to the discovery of a better conversion technology. If that were to occur then there would be no escalation in the value of existing on site solar systems and possibly even a decline. To call this, or the risk of a reactor core meltdown a market related risk is stretching the meaning of the CAPM.

One variation on the CAPM is a model tested by Miller and Scholes (ref. 28) in which thereis a term representing the unsystematic risk in an equation such as our (14). Although sampling problems make their conclusion less than clear cut, they found that this term was as significant a determinant of return as beta. Project cash flow variances can be estimated in a more or less straight-forward manner. These variances can in principle be separated into systematic and unsystematic components. Such an approach is probably more relevant on the case study level than the generic level because unsystematic risks are likely to vary considerably with region. Nonetheless this additional refinement on CAPM is probably the most promising path of development for the asses ment of financial risks associated with energy projects. In the case studies which will follow as the next phase of investigation we will explore this possibility.

\subsection{Conclusion}

This study is a preliminary attempt to develop a basis for distinguishing the elements of risk in energy projects. Financial risk is linked to required returns is estimating the feasibility of energy investments. We have found that utility investment in on site solar involves relatively few financial risks. This conclusion is more robust in comparing investments on the margin than in comparison with the historical record. Our results should not be interpreted as a claim of precise numerical differences. The data on which our estimates are based is far too limited for that. We do claim that 
our methods and qualitative conclusions are reasonable. Clearly, however, more reliable results can be achieved. In a period of rapidly rising capita1 requirements for energy and increasing uncertainty, it is desirable to develop an approach to distinguishing the financial risks of competing technologies. We hope to stimulate further work in both the specific application we have studied and in the genera1 problem. 
Tab1e 2

Fixed Charge Rates*

Coal vs. Nuclear

1. Annual Carrying Charges (ACR)

\begin{tabular}{|c|c|c|c|}
\hline & Nuclear & CoaI & $\begin{array}{l}\text { Reason for } \\
\text { Difference }\end{array}$ \\
\hline Return & $10.7 \ddot{8}$ & 10.58 & Financia1 Risk \\
\hline Depreciation & .94 & .45 & $\begin{array}{l}\text { Negative Net } \\
\text { Salvage Value }\end{array}$ \\
\hline Taxes (federa1) & $\frac{2.65}{14.37 \%}$ & $\frac{1.91}{12.94 \%}$ & \\
\hline
\end{tabular}

2. Construction Compound Interest Factor (CCIF)

$1.57 \quad 1.25 \quad$ Lead Time

3. Fixed Charge Rate $(F C R=A C R$ XCCIF $)$

$22.56 \% \quad 16.18 \%$

*Source: Testimony of Wm. Wood, SPEG, new Jersey Board of Public Utilities Commissioners, Docket No. 76z-194. 
REFERENCES

1. Otfice of Technology Assessment, Application of Solar Technology to Today's Energy Needs, Washington, D.C., June, $19 \overline{78, v} . \overline{1}$.

2. W. F. Sharpe, Portfolio Theory and Capital Markets, New York: McGraw-Hi11, 1970 .

3. J. Mossin, Theory of Financial Markets, Englewood Cliffs, New Jersey: Prentice-Ha $\overline{11,197 \overline{3}}$

4. F. Modigliani and G. Pogue, "An Introduction of Risk and Return: Concepts and Evidence," Financzal Analysts Journal (May-June, 1974) $69-86$.

b. 0. Vasicek, "A Note on Using Cross Sectional Information in Bayesian Estimates of Security Beta", Journal of Finance (December, 1973), 1233-1239.

6. B. Rosenberg and V. Marathe, "Prediction of Investment Risk: Systematic and Residual Risk" Proceedings: Seminar on Analysis of Security Prices. Grad. Sch. of Bus. Univ. of Chicago, 1975.

7. Federal Power Comm. et a1 vs Hope Natura1 Gas Company 320 US 591 (1949) at 603.

8. R.F. Vande11 and J.K. Malernee, "The Capital Asset Pricing Mode1 and Utility Equity Returns" Public Utilities Fortnightly (July 6, 1978)

9. Testimony of David K. Whitcomb before the State of New Jersey Board of Public Utilities Commissioners, Docket No. 7711-1136, June, 1978.

10. H.Averch and I. Johnson, "Behavior of the Firm Under Regulator Constraint" Am. Ec. Rev. (Dec. 1962) 1052-1069.

11. A, Kahn, The Economics of Regulation V.II New York, John Wiley, 1971.

12. W. W. Carpenter, "Marginal Cost: A Crıtique of its Progress" Electrical World (Apri1 1, 1978) pp 56-58.

13. S. Lee and C. Deschamps "Mathematica1 Mode1 for Economic Evaluation of Tidal Power in the Bay of Fundy", IEEE Summer Mectiny, Mexico City, July 17-22, 1977.

14. Roger Bezdek, An Analysis of the Current Economic Feasibility of Solar Water and Space Heating $\overline{\text { DOE } / \overline{C S-0023}, ~ J a n u a r y, ~} 1978$.

15. Booz, Allen and Hamilton, Inc., Utility Sponsored Home Insulation Programs, HCP/W1227-01 (June, 1978) 
16. Conversation with G. Amaroli, California Public Utilities Commission

17. B. Rosenberg \& J. Guy, "Prediction of Beta from Investment Fundamentals, "Financia1 Ana1ysts Journa1" (May-June, 1976) pp 60-7.2.

13. "Revised Data Show Uncollectibles Still High" Electrical World, January 15,1977 , pp 74-75

19. K. V. Smith, "The Effect of Intervaling on Estimating Pasmeters of the Capital Asset Pricing Model" Journal of Financial and Quantitative Analysis (June, 1978) pp 313- $\overline{332}$

20. California Energy Resources Conservation and Development Commission, Biennial Report Towards a California Energy Strategy: Policy Overview, Sacramento, California $1 \overline{9} \overline{7}$

21. R. A. Haugen, A. L. Stroyny and D. W. Wichern, "Rate Regulation, Capita1 Structure and the Sharing of Interest Rate Risk in the Electric Utility Industry", Journal of Finance, vol. 33 (June, 1978), pp 707-721

22. California Public Utilities Commission, Interim Opinion, Decision No. 86281, August 24, 1976

23. Pacific Gas and Electric Co., Responses to Commission, Order 77-622-14, submitted to California ERCDC, September 30, 1977

24. W.R.Z. Willey, Alternate Energy Systems for Pacific Gas and Electric Co., An Economic Analysis, Environmental Defense Fund, Berkeley, California, $\overline{1978}$

25. S. C. Myers and S. M. Turnbu11, "Capita1 Budgeting and the Capital Asset Pricing-Mode1:-Good-News-and-Bad-News," Journal of Einance,,_vo1._. 32, (May, 1977) pp 321-333.

26. Testimony of William Wood, Public Service Electric and Gas Co., before New Jersey Board of Public Utility Commissioners, Docket No. 762-194, Exhibit PST-4, 1978

27. J. W. Doane, R. P. O'Toole, R. G. Chamberlain, P. B. Bos and P. D. Maycer1e, The Cost of Energy from Utility-Owned Solar Electric Systems, ERDA/JPL$\overline{1012}-76 / 3$, June, $\overline{1976}$

28. M. H. Miller and M. S. Scholes, "Rates of Return in Relation to Risk: A Re-examination of Recent Findings", Studies in the Theory of Capital Markets, ed. Michae1 Jensen, New York: Praegar, $1 \overline{972}$

29. Southwest Energy Management, Inc., Multi-Family Solar Water Heating, Final Report to California Energy Commission, June 29, $\overline{1978}$

30. Arthur D. Little, Inc., California Clean Fuels Study, Cambridge, April, 1978

31. Pacific Gas and Electric Co., Forecast of the Denand for Electricity and Natura1 Gas Within Pacific Gas and Electric Company Service Area, 19771978, February 1978

32. S. L. Feldman and B. Andersen, Utility Pricing and Solar Energy Design, Fina1 Report NSV/RANN \#APR-75-18006, Sept. 30, 1976. 


\section{APPENDIX 1}

\section{Derivation of CAPM}

To prove

$$
\frac{\partial R_{p}}{\partial \sigma_{p}}=\frac{R_{m}-R_{f}}{\sigma_{m}} \text { implies CAPM }
$$

Define

$$
R_{p}=x_{i} R_{i}+x_{m} R_{m}
$$

Where

$$
\begin{aligned}
& x_{i}+x_{m}=1 . \quad \begin{array}{l}
\text { These are the shares of the asset } i \\
\text { and the market portfolio } m \text { in the } \\
\text { portfolio } P .
\end{array}
\end{aligned}
$$

Then

$$
\sigma_{p}^{2}=x_{i}^{2} \sigma_{i}^{2}+x_{m}^{2} \sigma_{m}^{2}+2 x_{i} x_{m} \operatorname{Cov}\left(R_{i}, R_{m}\right)
$$

Substitute

$$
x_{m}=\left(1-x_{i}\right)
$$

Then

$$
\sigma_{p}=\left[x_{i}^{2} \sigma_{i}^{2}+\left(1-x_{i}\right){ }^{2} \sigma_{m}^{2}+2 x_{i}\left(1-x_{i}\right) \operatorname{Cov}\left(R_{i}, R_{m}\right)\right] 1 / 2
$$

and

$$
\frac{\partial \sigma_{p}}{\partial X_{i}}=\frac{x_{i}\left(\sigma_{i}^{2}+\sigma_{m}^{2}-2 \operatorname{Cov}\left(R_{i}, R_{m}\right)\right)+\operatorname{COV}\left(R_{i}, R_{m}\right)-\sigma_{m}^{2}}{p}
$$

Substitute $x_{m}=\left(1-x_{i}\right)$ into expression for $R_{p}$ and differentiate with respect to $X$.

Then

$$
\frac{\partial R_{p}}{\partial x_{i}}=R_{i}-R_{m}
$$

$$
\begin{aligned}
& \frac{\partial \mathrm{R}_{\mathrm{p}}}{\partial \sigma_{\mathrm{p}}}=\frac{\partial \mathrm{R}_{\mathrm{p} /} \partial \mathrm{X}_{i}}{\partial \sigma_{\mathrm{p}}{ }^{\partial \mathrm{X}_{i}}} \\
& =\frac{\left(\mathrm{R}_{i}-\mathrm{R}_{\mathrm{m}}\right) \sigma_{p}}{\left[\mathrm{X}_{i}\left(\sigma_{i}^{2}+\sigma_{\dot{m}}{ }^{2}-2 \operatorname{COV}\left(\mathrm{R}_{i} \mathrm{R}_{m}\right)\right)+\operatorname{COV}\left(\mathrm{R}_{i}, \mathrm{R}_{m}\right)-\sigma_{m}{ }^{2}\right]}
\end{aligned}
$$

We are interested in the value of this derıvative at the point where the portfolio $\mathrm{p}$ consists onIy of the market portfolio $\mathrm{m}$, i.e. whereas $\mathrm{x}_{i}=0$ and $\sigma_{\mathrm{p}}=\sigma_{\mathrm{m}}$. 
Making these substitutions we obtain

$$
\left.\frac{\partial \mathrm{R}_{\mathrm{p}}}{\partial \sigma_{\mathrm{p}}}\right|_{i=0}=\frac{\mathrm{R}_{i}-\mathrm{R}_{\mathrm{m}}}{\left(\operatorname{Cov}\left(\mathrm{R}_{i}, \mathrm{R}_{\mathrm{m}}\right)-\sigma_{\mathrm{m}}^{2}\right) / \sigma_{\mathrm{m}}}
$$

Finally we equate this expression with the slope of the capital market line and derive the CAPM.

$$
\begin{aligned}
& \frac{\left(R_{i}-R_{m}\right) \sigma_{m}}{\operatorname{COV}\left(R_{i}, R_{m}-\sigma_{m}^{2}\right.}=\frac{R_{m}-R_{f}}{\sigma_{m}}, \\
& \left(R_{i}-R_{m}\right) \sigma_{i n}^{2}=\left(R_{m}-R_{f}\right)\left(\operatorname{COV}\left(R_{i}, R_{m}\right)-\sigma_{m}^{2}\right), \\
& R_{i} \sigma_{m}^{2}=R_{m} \sigma_{m}^{2}+R_{m} \operatorname{COV}\left(R_{i}, R_{m}\right)-R_{m} \sigma_{m}^{2}-R_{f} \operatorname{COV}\left(R_{i}, R_{m}\right)+R_{f} \sigma_{m}^{2}, \\
& \left.\left(R_{i}-R_{f}\right) \sigma_{m}^{2}=R_{m}-R_{f}\right) \operatorname{COV} \cdot\left(R_{i}, R_{m}\right), \\
& R_{i}-R_{f}=\left(R_{m}-R_{f}\right) \operatorname{COV} \frac{\left(R_{i}, R_{m}\right)}{\frac{\sigma_{m}{ }^{2}}{{ }^{2}} .}
\end{aligned}
$$

This expression is the CAPM. 
APPENDIX 2

Risk Measure for Projects

Notation: Capital letters are returns in dollars. Small letters are rates of returns. Primes indicate the situation after investment I has been made.

Start with CAPM:

$$
E\left(r_{c}\right)-r_{f}=\left[E\left(r_{m}\right)-r_{f}\right] \beta_{c}
$$

After undertaking a desirable project $I$, we have

$$
\begin{aligned}
& E\left(r_{c}^{\prime}\right)-r_{f}>\left[E\left(r_{m}\right)-r_{f}\right] \beta_{c}^{\prime} \\
& \frac{E\left(r_{c}^{\prime}\right)-r_{f}}{\beta_{c}^{\prime}}>\frac{E\left(r_{c}\right)-r_{f}}{\beta_{c}} \\
& \dot{r}_{c}=\frac{R_{c}}{C_{c}} ; r_{c}^{\prime}=\frac{R_{c}+R_{I}}{C_{c}+I} \\
& \mathrm{r}_{\mathrm{m}}=\frac{\mathrm{R}_{\mathrm{m}}}{\mathrm{C}_{\mathrm{m}}} ; \mathrm{r}_{\mathrm{m}}^{\prime}=\frac{\mathrm{R}_{\mathrm{m}}+\mathrm{R}_{\mathrm{I}}}{\mathrm{C}_{\mathrm{m}}+\mathrm{I}} \\
& \beta_{c}=\frac{\operatorname{Cov}\left(r_{c}, r_{m}\right)}{\operatorname{Var}\left(r_{m}\right)} ; \beta_{c}^{\prime}=\frac{\operatorname{Cov}\left(r_{c}^{\prime}, r_{m}^{\prime}\right)}{\operatorname{Var}\left(r_{m}^{\prime}\right)} \\
& r_{m}^{\prime}=\frac{R_{m}}{C_{m}}\left(\frac{C_{m}}{C_{m}+I}\right)+\frac{R_{I}}{I}\left(\frac{I}{C_{m+I}}\right)=r_{m}\left(\frac{C_{m}}{C_{m}+I}\right)+r_{I}\left(\frac{I}{C_{m}+I}\right) \\
& r_{c}^{\prime}=\frac{R_{c}}{C_{c}}\left(\frac{C_{c}}{C_{c}+I}\right)+\frac{R_{I}}{I}\left(\frac{T}{C_{c}+I}\right) \\
& r_{c}^{\prime}=r_{c}\left(\frac{C_{c}}{C_{c}+I}\right)+r_{I}\left(\frac{I}{C_{c}+I}\right)
\end{aligned}
$$


The new rate of return is the capitalization weighted average of the new project and the company before the project.

$$
\frac{\beta_{c}=\operatorname{Cov}\left\{\left[\left(\frac{C_{c}}{C_{c}+I}\right)^{\left.\left.r_{c}+\left(\frac{I}{C_{c+} I}\right)^{r_{1}}\right],\left[\left(\frac{C_{m}}{C_{m}+I}\right) r_{m}+\left(\frac{I}{C_{m}+I}\right)^{r_{I}}\right]\right\}}\right.\right.}{\operatorname{Var}\left\{\left(\frac{C_{m}}{C_{m}+I}\right) r_{m}+\left(\frac{I}{C_{m}+I}\right)^{r} I\right\}}
$$

Examine Numerator:

$$
\begin{aligned}
& \operatorname{Cov}\{\}=\frac{C_{c} C_{m}}{\left(C_{c}+I\right)\left(C_{m}+I\right)} \operatorname{Cov}\left(r_{c}, r_{m}\right)+\frac{I C_{m}}{\left(C_{c}+I\right)\left(C_{m}+I\right)} \operatorname{Cov}\left(r_{I}, r_{m}\right) \\
& +\frac{C_{c} I}{\left(C_{c}+I\right)\left(C_{m}+I\right)} \operatorname{Cov}\left(r_{c}, r_{I}\right)+\frac{I^{2}}{\left(C_{c}+I\right)\left(C_{m}+I\right)} \operatorname{Var}\left(r_{I}\right)
\end{aligned}
$$

Notice that the last three terms include the covariances identified in Eq. (6) Sec. 2.4, but they are weighted by capitalization. We will approximate this entire expression for the case in which the investment $I$ is $10 \%$ of the firm's capitalization.

$$
\begin{aligned}
& \text { Assume: } I \ll \mathrm{C}_{\mathrm{m}} \\
& \frac{\mathrm{I}}{\mathrm{C}_{\mathrm{c}}} \sim .1 \\
& \frac{\mathrm{C}_{\mathrm{c}} \mathrm{C}_{\mathrm{m}}}{\left(\mathrm{C}_{\mathrm{c}}+\mathrm{I}\right)\left(\mathrm{C}_{\mathrm{m}}+\mathrm{I}\right)} \stackrel{\sim}{\sim} \frac{\mathrm{C}_{\mathrm{c}}}{\mathrm{C}_{\mathrm{c}}+\mathrm{I}} \sim .9 \\
& \frac{\mathrm{I} \mathrm{C} \mathrm{m}_{\mathrm{m}}}{\left(\mathrm{C}_{\mathrm{c}}+\mathrm{I}\right)\left(\mathrm{C}_{\mathrm{m}}+\mathrm{I}\right)} \approx \frac{\mathrm{I}}{\mathrm{C}_{\mathrm{c}}+\mathrm{I}} \sim .1 \\
& \frac{C_{c}}{\left(C_{c}+I\right)\left(C_{m}+I\right)} \approx 0 \\
& \frac{I^{2}}{\left(\mathrm{C}_{\mathrm{c}}+\mathrm{I}\right)\left(\mathrm{C}_{\mathrm{m}}+\mathrm{I}\right)} \approx 0
\end{aligned}
$$


$\operatorname{Cov}\{\} \approx \frac{C_{c}}{C_{c}+I} \quad \operatorname{Cov}\left(r_{c}, r_{m}\right)+\frac{I}{C_{c}+I} \operatorname{Cov}\left(r_{I}, r_{m}\right)$

Examine demominator:

$\operatorname{Var}\left\{\left\{\frac{\mathrm{C}_{m}^{2}}{\left(\mathrm{C}_{\mathrm{m}}+\mathrm{I}\right)^{2}} \quad \operatorname{Var}\left(\mathrm{r}_{\mathrm{m}}\right)+\frac{I^{2}}{\left(\overline{\left.\mathrm{C}_{m}+I\right)^{2}}\right.} \quad \operatorname{Var}\left(\mathrm{r}_{\mathrm{I}}\right)+\frac{2 \mathrm{C}_{m} I}{\left(\overline{\mathrm{C}_{m}+\mathrm{I}}\right)^{2}} 2 \operatorname{Cov}\left(\mathrm{r}_{\mathrm{m}}, \mathrm{r}_{\mathrm{I}}\right)\right.\right.$

Using previous approximations:

$$
\begin{aligned}
& \operatorname{var}\{\} \approx \operatorname{var}\left(r_{m}\right) \\
& \beta_{c}^{\prime} \approx\left(\frac{C_{c}}{C_{c}+1}\right) \text { Cov }\left(r_{c}, r_{m}\right)+\left(\frac{I}{C_{c}+I}\right) \text { Cov }\left(r_{I}, R_{m}\right) \\
& \frac{\operatorname{var}\left(r_{m}\right)}{}
\end{aligned}
$$

$$
\beta_{c} \approx\left(\frac{C_{c}}{C_{c}+I}\right) \beta_{c}+\left(\frac{I}{C_{c}+I}\right) \beta_{I}
$$

Thus, the new beta for the company is the capitalization weighed average of the original beta and the project beta. In this approximation the project beta, $\beta_{I}=\frac{\operatorname{Sov}\left(r_{I}, r_{m}\right)}{\operatorname{VAR}\left(r_{m}\right)}$ and we can neglect the higher order terms.

Fina11y, we

$$
\begin{aligned}
& \text { Substitute 2. and } 3 \text {. into } 1 \text {. }
\end{aligned}
$$

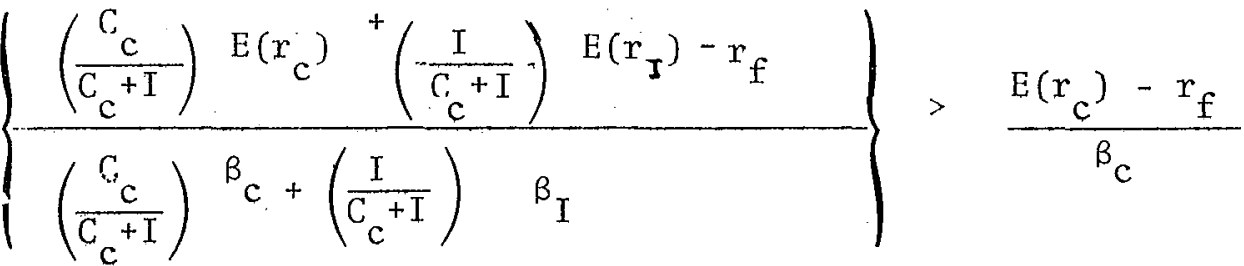


Project is desirable if:

$\left\{\left(\frac{\mathrm{C}_{\mathrm{c}}}{\mathrm{C}_{\mathrm{c}}+\mathrm{I}}\right) \mathrm{E}\left(\mathrm{r}_{\mathrm{c}}\right) \beta_{\mathrm{c}}+\left(\frac{\mathrm{I}}{\mathrm{C}_{\mathrm{c}}+\mathrm{I}}\right) \mathrm{E}\left(\mathrm{r}_{\mathrm{I}}\right) \beta_{\mathrm{c}}-\mathrm{r}_{\mathrm{f}} \beta_{\mathrm{c}}\right\}>\left\{\left(\frac{\mathrm{C}_{\mathrm{c}}}{\mathrm{C}_{\mathrm{c}}+1}\right) \quad \beta_{c} \mathrm{E}\left(\mathrm{r}_{\mathrm{c}}\right)\right.$

4.

$\left.+\left(\frac{I}{C_{c}+I}\right){ }^{\beta} I E\left(r_{c}\right)-\left(\frac{C_{c}}{C_{c}+I}\right){ }^{\beta}{ }_{c}\left(r_{f}\right)-\left(\frac{I}{C_{c}+I}\right){ }^{\beta_{I}} r_{f}\right\}$.

Simplifying,

$\left(\frac{I}{C_{c}+I}\right) \quad E\left(r_{I}\right) \quad \beta_{c}-\left(\frac{I}{C_{c}+I}\right) r_{f} \beta_{c}>\left(\frac{I}{C_{c}+I}\right){ }^{\beta_{I}} E\left(r_{c}\right)-\left(\frac{I}{C_{c}+I}\right)^{\beta_{I}} r_{f}$

This reduces to

$\left(E\left(r_{I}\right)-r_{f}\right) \beta_{c}>\left(E\left(r_{c}\right)-r_{f}\right) \beta_{I}=\left(E\left(r_{m}\right)-r_{f}\right) \beta_{c} \beta_{I}$.

Therefore, if the project's excess return satisfies (5) it is desirable

$\left(E\left(r_{I}\right)-r_{f}\right)>\left(E\left(r_{m}\right)-r_{f}\right) \quad \beta_{I}$

(5).

-This equation is-identical-to-eq-(7)-in-section -2.4. 
APPENDIX 3

The Procedure used in the Calculation of the

Systematic Risk Measure $\beta$

The Capital Asset Pricing Model presumes that associated with each and every capital asset there is an expected rate of return denoted by $r$, and a systematic risk measure denoted by $\beta$. The expected rate of return depends on the amount and timing of expected future cash flows, and on the initial cost of the asset. The systematic risk measure depends on the degree to which the asset return co-varies with the average return on all assets. (i.e. with the economy as a whole). More precisely, $\beta$ is defined by:

$$
\beta_{i}=\frac{\text { Covariance }\left(r_{i}, r_{M}\right)}{\text { Variance }\left(r_{M}\right)}
$$

Where the subscript $i$ denotes a particular asset and the subscript $M$ denotes the market average.

The two different techniques commonly used to evaluate $\beta$ are referred to as the fundamental and the technical methods respectively. The fundamental method is based on the following definitions:

$$
\begin{aligned}
& \text { Covariance }\left(R_{i}, R_{m}\right)=\sum_{\bar{n}} P_{n} \times\left(R_{i n}-\bar{R}_{i}\right) \times\left(R_{m n}-\bar{R}_{m}\right) \\
& \text { Variance }\left(R_{m}\right)=\sum_{n} P_{n} \times\left(R_{m n}-\bar{R}_{m}\right)^{2}
\end{aligned}
$$

Where $n$ denotes a possible state of the economy, $P_{n}$ denotes the estimated probability of that state eventuating, $R_{i n}$ denotes the estimated rate of return on asset $i$ in economic state $n$ and $R_{m n}$ denotes the estimated market average rate of return in economic state $n$.

The technical method for evaluating $\beta$ is based on the fact that the definition of $\beta_{i}$ as given by Equation 1 is also the formula for the coefficient of a simple regression. Thus $\beta_{i}$ can be calculated from a regression of past 
values of $r_{i}$ on past values of $r_{m}$. The above formulation is referred to as the Market Mode1 and the underlying regression equation takes the form:

$$
R_{i}=\alpha_{i}+\beta_{i} R_{m}+e_{i}
$$

where $\alpha_{i}$ is the regression intercept term, and $e_{i}$ is a stochastic error term.

The data set used spanned the interval from January 1968 to December 1977. The composite market and composite utilities' index rates of return were ca1culated from the respective Standard and Poor's monthly-average price and yield indices. The rates of return for individual utilities were based on published common stock price and dividend data. In the case of individual stocks, the monthly returns was calculated by adding the monthly price change gain to the monthly dividend return. The above relations can be expressed as:

$$
r_{i}(t)=d_{i}(t) / 12+\frac{P_{i}(t+1)-P_{i}(t)}{P_{i}(t)}
$$

Where $d_{i}(t)$ is the yearly average dividend yield of stock $i, P_{i}(t)$ is the average price of stcok.

The computations were carried out using 60 month sub-blocks of data with the first sub-block spanning the interval from January 1968 to December 1972 and subsequent sub-blocks spanning $60^{-}$month intervals commencing with February-1968, Maxch 1968, etc. The calculations of $\beta$ for each asset $i$ were therefore performed on 61 sub blocks in a11. The results of these calculations appear in Figures Al through A4. 
Variation of Beta Over Time (60 month intervals)

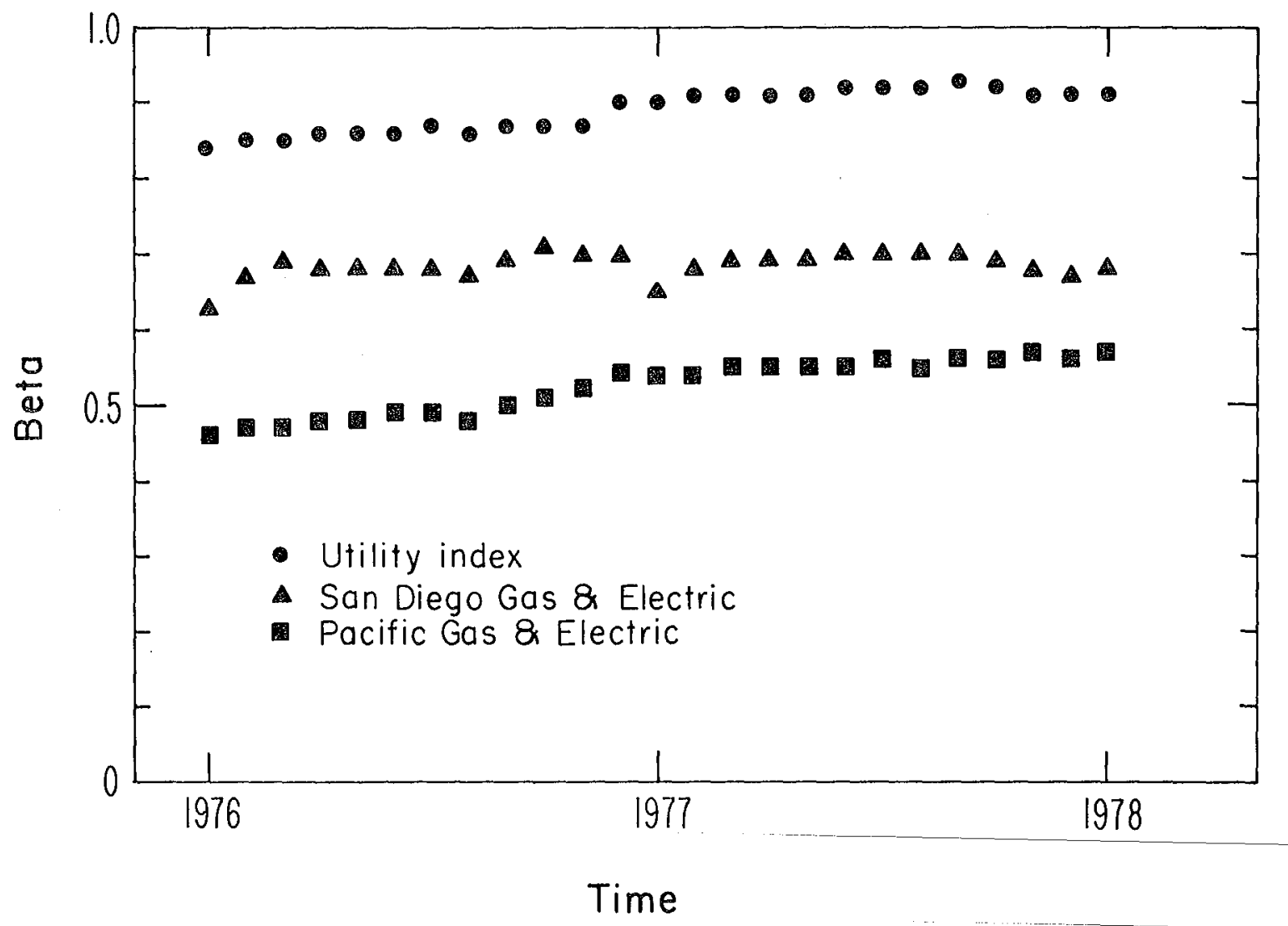

XBL $789-2677$ 
Beta for Standard and Poor's Utility Index

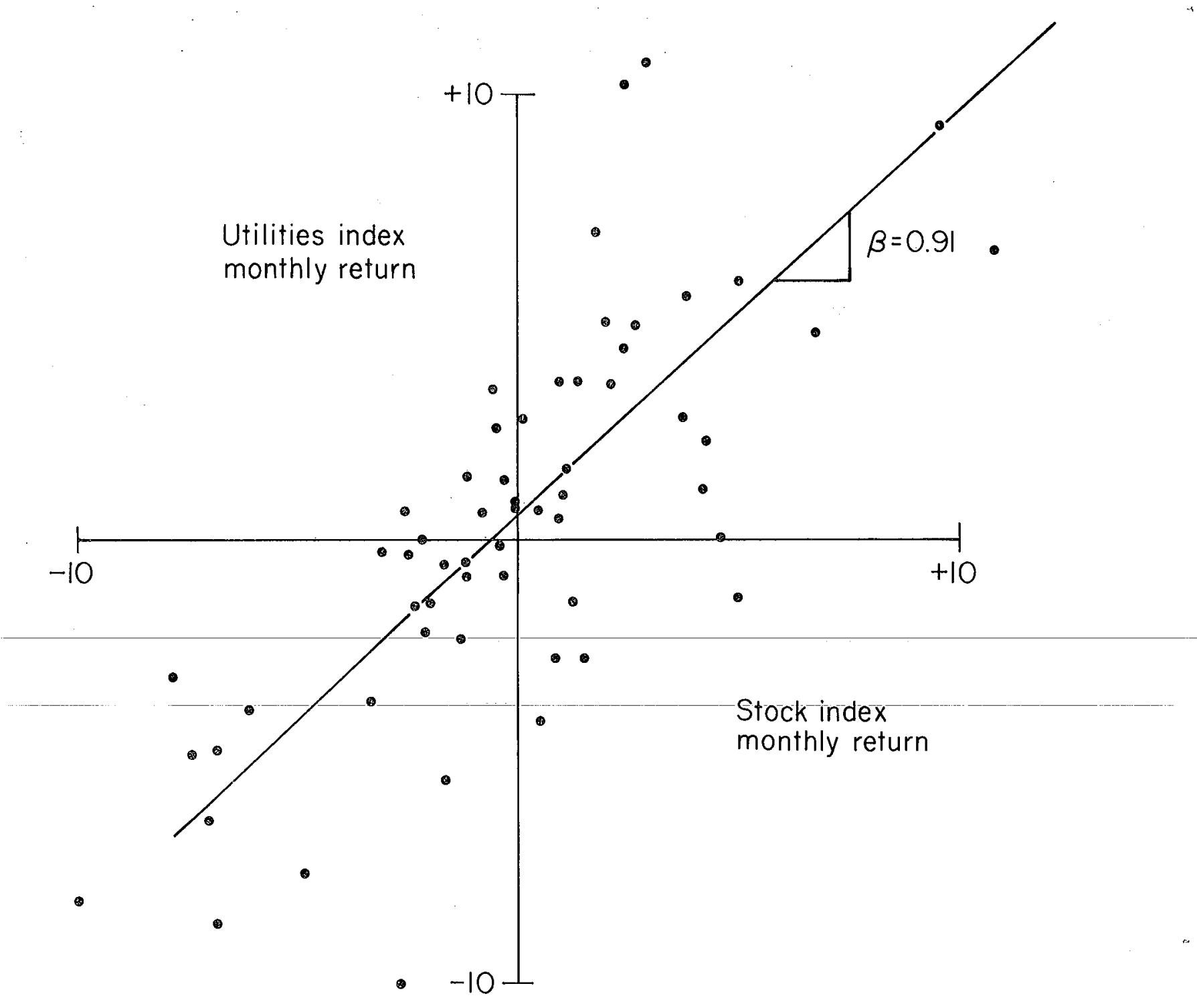


San Diego Gas \& Electric Co. Beta

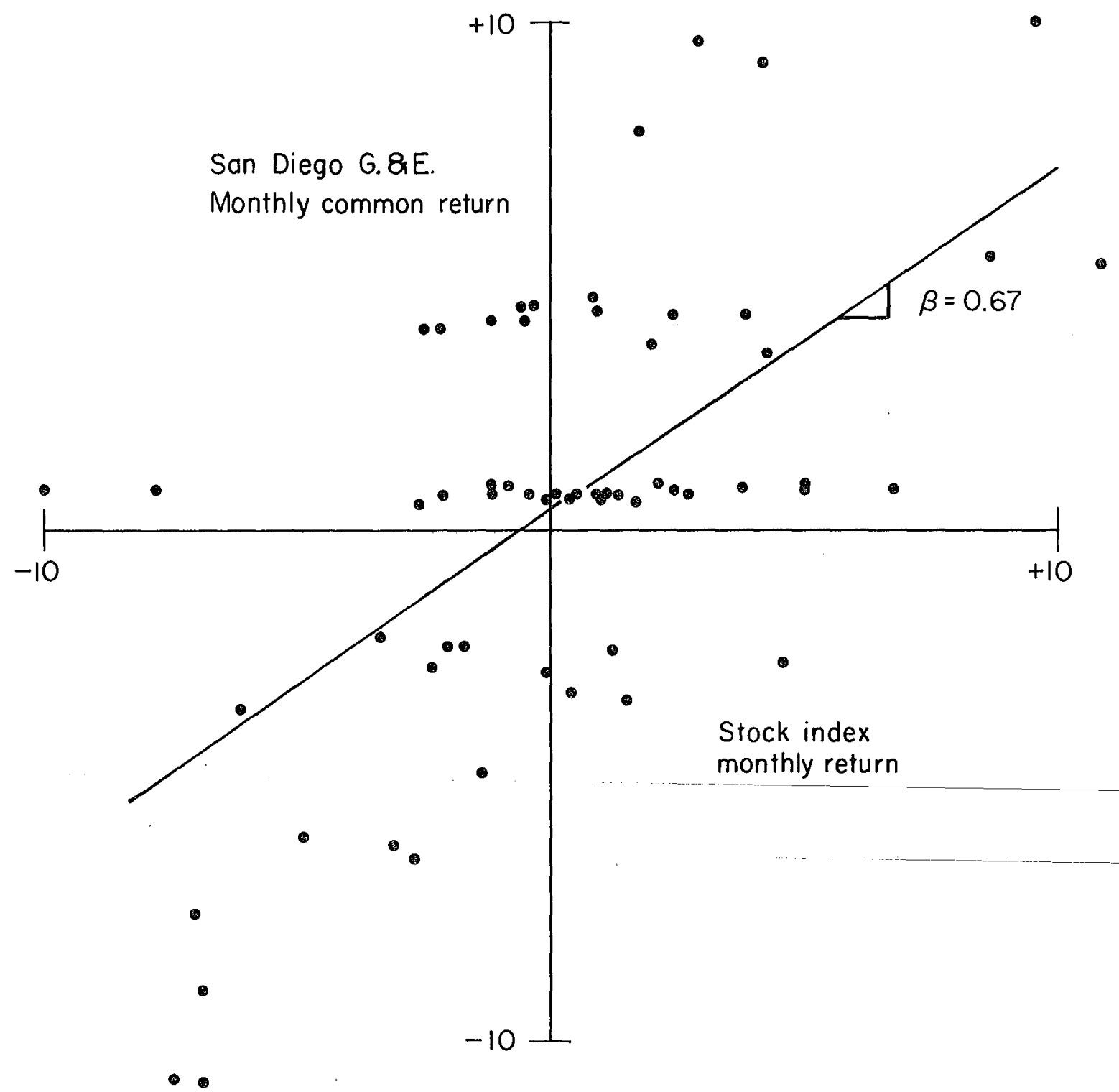


Pacific Gas \& Electric Co. Beta

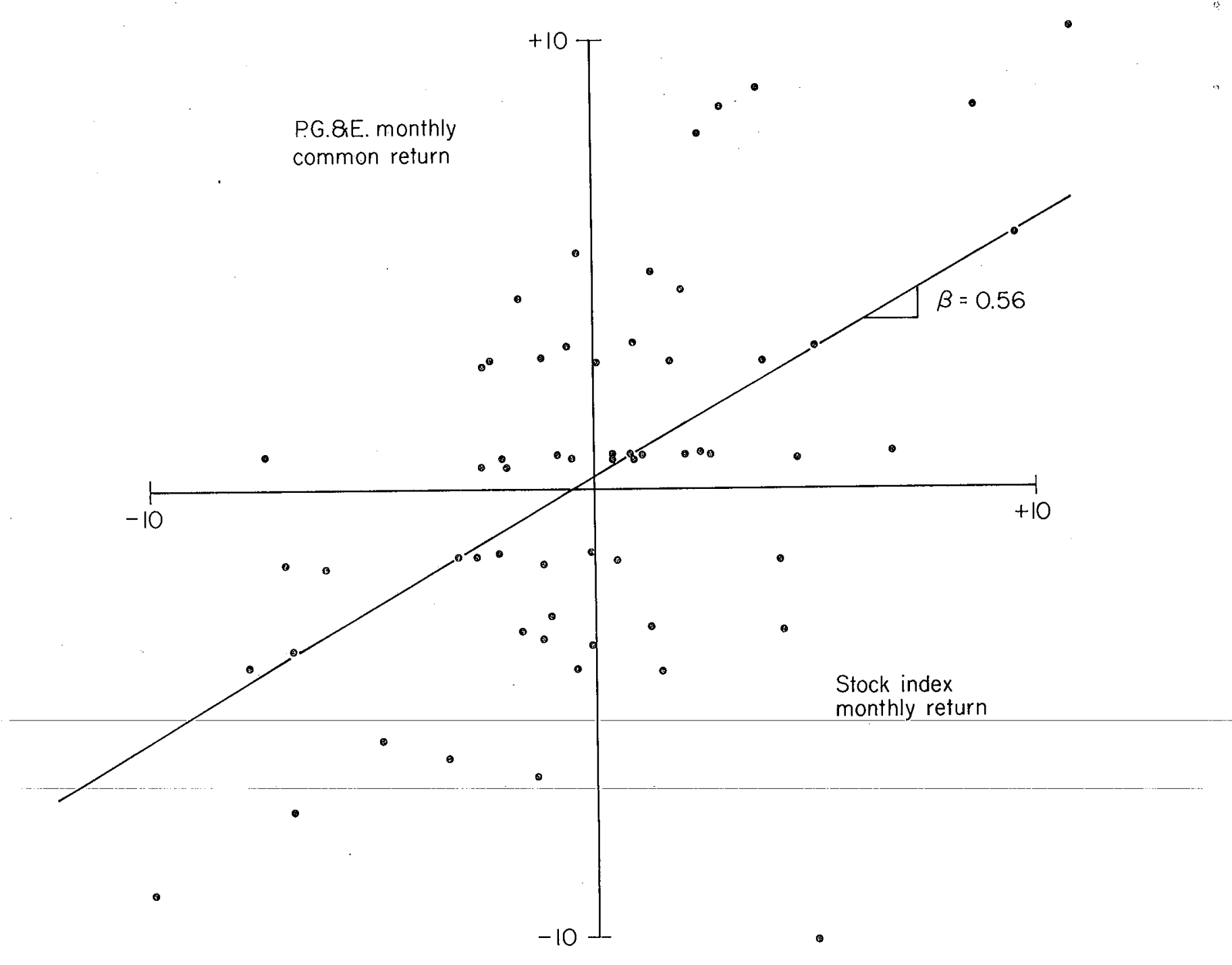

XBL 789-2679 
APPENDIX 4

The Stability of Technical $\beta$

As discussed in Appendix 3, the $\beta^{\prime}$ s used in this study were calculated from regressions, using historical data, of the assets' rate of return on the market rate of return. In effect, historical data were used as a sample from which sample $\beta^{\prime}$ s were calculated. As with all statistical estimations, the precision with which the sample estimator reflects the true parameter (in this case $\beta$ ) improves with increasing sample size. On the other hand, increasing the sample size, in this case, means using data from future into the past. Thus the sample size must be large enough to give a meaningful estimate of $\beta$ but not extend so far back into the past that the results reflect past rather than current values of $\beta$.

Thus, choosing the appropriate sample size involves a tradeoff between statistical precision and temporal accuracy. In this study $\beta$ 's were calculated from sample intervals of 6 months, 12 months, 18 months, 24 months, 30 months and 60 months. Figures A5 and A6 show the values of $\beta$ calculated for Pacific Gas and Electric Company common stock and for the Standard and Poor's 40 stock utilities index using differing sample intervals.

From the data it is clear that increasing the size of the sample interval reduces the statistical scatter in the calculated values of $\beta$. It would also appear that the underlying values of $\beta$ did change significantly over the 10 year interval spanned by the data set. Thus, the appropriate length of the sample interval must be chosen with the above trade off in mind.

For the purposes of this study it was decided that a 60 month sample interval would be appropriate. This is also the sample interval used by Whitconb (1978). Figures A5 and A6 show that for this sample interval the statistical scatter in the data is small compared to the numerical values of $\beta$. The figures a1so show that there is less statistical scatter when using the utilities index data than in the individual securities' data. This is due to the fact that fluctuations present in individual data points tend to be smoothed out when individual securities data are combined into an index. 
Beta Scatter as a Function of Averaging Interval: Utilities Index
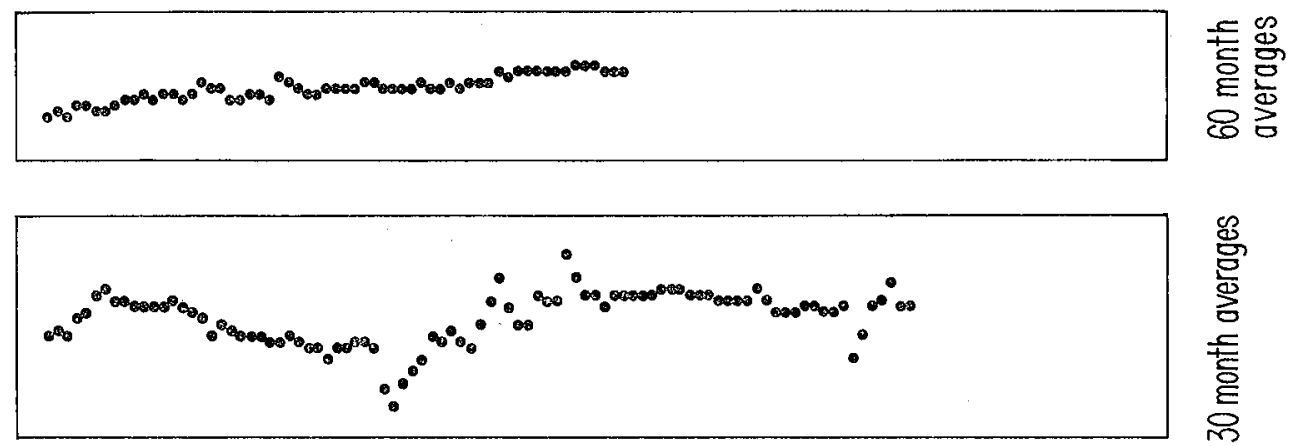

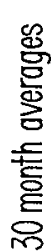

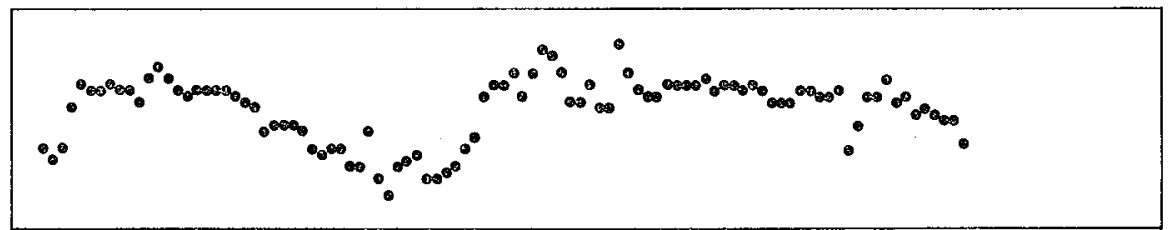

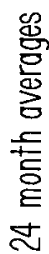

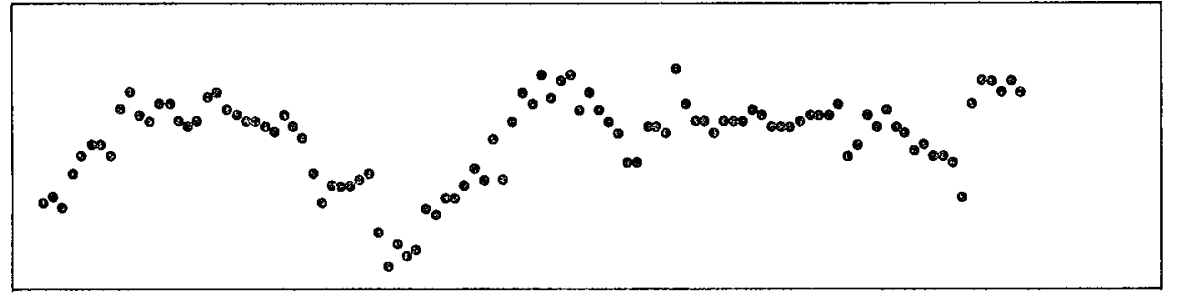

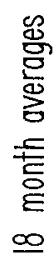
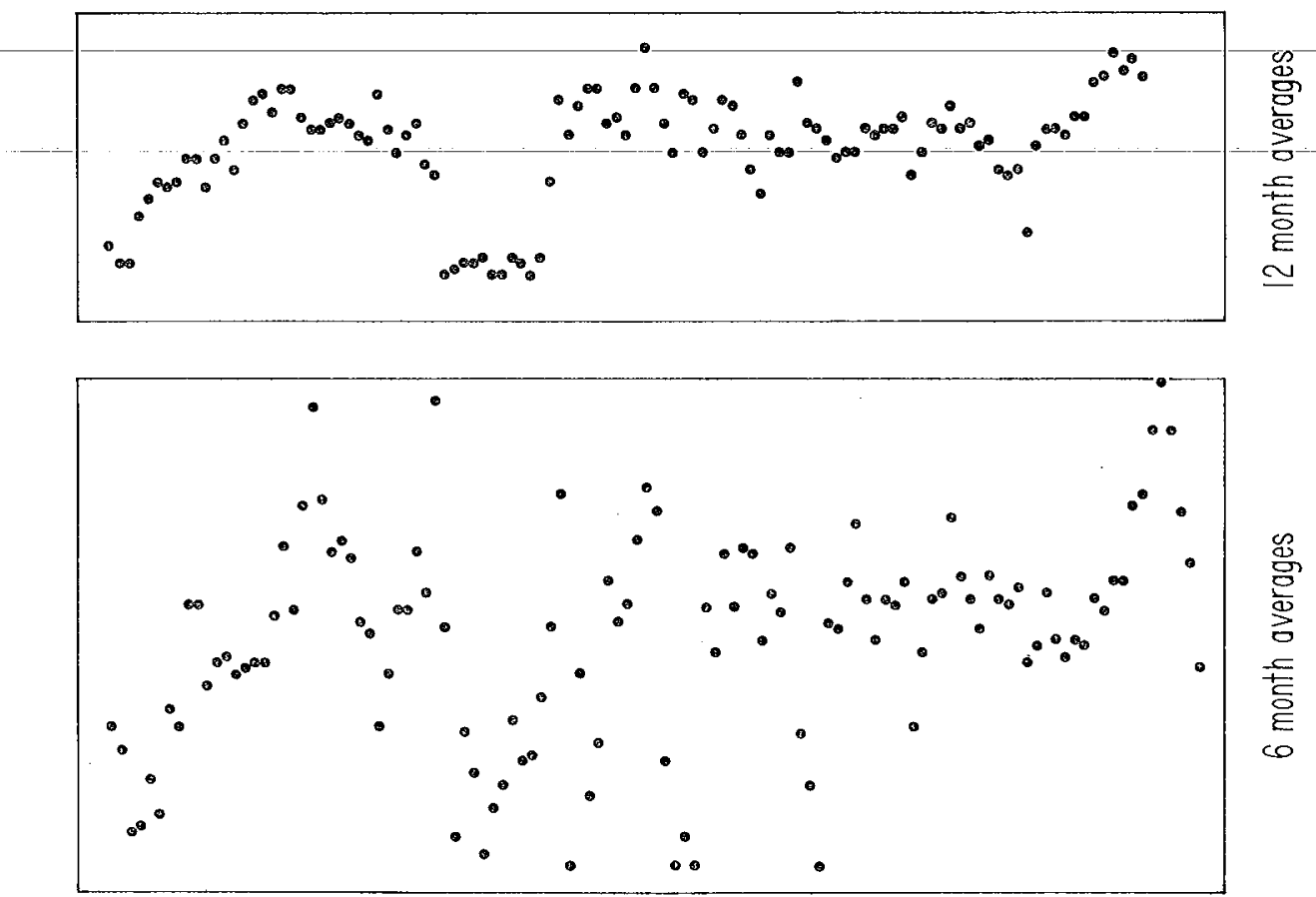
Beta Scatter as a Function of Averaging Interval: Pacific Gas \& Electric
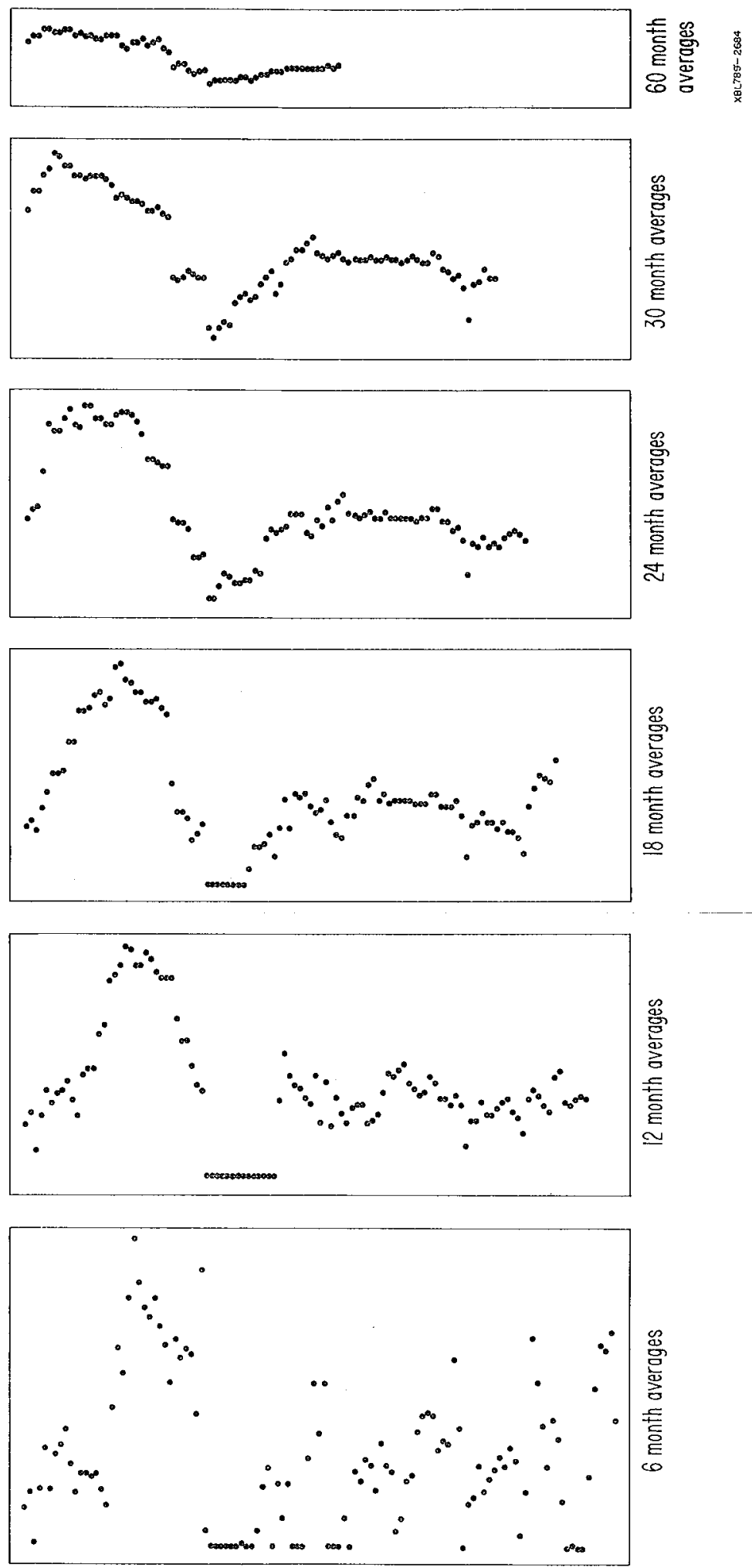


\section{APPENDIX 5}

\section{Determination of $\beta$ for On Site Solar Heating}

Of the two techniques discussed in Appendix 3 for determining the $\beta$ of a capital asset, on $1 y$ the fundamental technique can be applied directly to new capital investments. The technical method can, however, be applied indirectly to estimate the $\beta$ of new capital projects. This is accomplished by identifying existing capital assets having risk characteristics similar to those expected in the new capital investment. In effect one estimates the $\beta$ of a new investment by using the technical $\beta$ of existing assets having similar risk properties as proxies for the new project beta.

As discussed in the text, the excess capacity risk associated with On Site Solar Heating could be expected to be sma11 and would result almost exclusively from housing units, for which the investment in On Site Solar Heating Systems was made, going unoccupied. To determine the magnitude of this risk, a regression of housing occupancy rates on the Standard and Poor's 500 composite stock index rates of return was performed. The vacancy rates used in the regression were the quarterly vacancy rates for rental units for the western United States published by the Department of Housing and Urban Development. The results of the analysis are reproduced in Figure $\mathrm{A7}$, and indicate that, to any reasonable confidence level, the regression coefficient of occupancy rate on riarket rate of return is zero. Therefore, while the amount of unused capacity will certainly not be zero, it should not vary in a systematic way with the market. Thus, excess capacity risk would affect the expected rates of return of On Site Solar Heating systems, but would not contribute to the systematic risk, $\beta$.

The major market risk in the On Site Solar Heating investment results from the long term nature of the investment. Whenever a long term investment is undertaken there is always the risk that better uses for that capital will be found in the future. This is evidenced by the fact that long term interest rates, even for riskless government securities, are higher than short term interest rates. 
In order to determine the value of $\beta$ that reflects this long term interest rate associated with the On Site Solar Heating investment, the Standard and Poor's High Grade Corporate Bond Index was selected as a reasonable proxy. The bonds rates of return is given by:

$$
R(t)=\frac{d^{*}(t)}{12}+\frac{P^{*}(t+1)-P^{*}(t)}{P^{*}(t)}
$$

Where $d^{*}(t)$ is the virtual dividend yield assuming a four percent coupon rate, $P^{*}(t)$ is the conversion price of the bond index at time $t$. The conversion price is the price of a hypothetical four percent coupon, twenty years to maturity of a bond that would have the same yield to maturity as the Standard and Poor's sample. The results of the regression of bond index rates of rereturn on market rates of return are given in Figure A8.

We have chosen this regression to represent the long-term interest rate risk because it is the latest value calculated over the five-year averaging interval. The choice of this averaging interval is consistent with out other regression estimates for beta's. Nonetheless, as Appendix 4 indicates the scatter of beta estimates varies considerably with the averaging interval used. To put the value $\beta-0.14$ in some perspective we will reproduce in Table A5-1 below some other regression estimates of the corporate bond index beta as a function of averaging interval. These data show the same phenomena we have seen in Appendix 4. As the averaging interval decreases, the range of variation grows in the estimated value as do the standard errors. It should also be noted that the latest value estimated shows considerable variation. Thus, while it is not obvious which of the many values to rely on, at least for the longer averaging intervals the average of high and low estimates is consistent with the adopted value of $\beta=0.14$. Some kind of "average of the averages" is the appropriate choice for a project beta estimate. Still the data are not wholly inconsistent with solar beta estimates of even twice our adopted value. This change would not alter our qualitative conclusion that on-site solar risks are low for utility investment, but it might increase the estimated finance charge to as much as $9.5 \%$. 
A7

Housing Occupancy Rate Regressed on

Stock Market Index Rate of Return

\begin{tabular}{|c|c|c|c|c|}
\hline INGSAD & YAcRAC & & & \\
\hline G.6724? & 0,21111 & 94.19754 & BE TA A & SE \\
\hline n. 92655 & 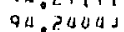 & $Q 4.23 ? 83$ & : $01010^{10}$ & $\begin{array}{l}.100752 \\
: 00691\end{array}$ \\
\hline 7.59393 & 94.32778 & 94,30343 & c0315 & innsan \\
\hline 5.23990 & $04,32 ?>2$ & 94.20611 & .00409 & .00497 \\
\hline $10.097 \mathrm{BI}$ & a . दोर? & 94,24171 & .00650 & .00553 \\
\hline 5.68075 & $94.2555 t$ & 44,22211 & - COSAa & .00562 \\
\hline 0.29382 & प1 , गКमАG & 94.27137 &.$O O \triangle O A$ & .00512 \\
\hline$\times .326409$ & Q1", ?hent & 94.25171 & 00050 & .00515 \\
\hline 2.19909 & $0.15 n n n$ & 94.13200 & .00814 & .00459 \\
\hline. .35037 & $04.11+67$ & 04,11035 & .011166 & .00404 \\
\hline 3.47095 & au. inomen & $24, n 6690$ & .00952 & กOSAA \\
\hline 0.63741 & as nosuas & 90.01540 & :nOb?h & . OOB Bas \\
\hline 9.31090 & $43.97 ? 28$ & 93,95510 & 011394 & $0039 \mathrm{~A}$ \\
\hline 1.31375 & $93.8977^{8}$ & 03.4738 ? & .00301 & :nouta \\
\hline 1.33125 & Q $3.4+334$ & Q3,Fด187 & notion & .00393 \\
\hline 5.04000 & 43.92774 & $03.9902^{\circ}$ & .00536 &.$\cap 039 A$ \\
\hline 4,90941 & 93,90550 & 93,89287 & .00459 & .00385 \\
\hline 3.39017 & $43.9000 \mathrm{~m}$ & 93 , RAB 14 & .100350 & 00389 \\
\hline 4.20243 & 93,03333 & 93,91640 & $.004 n ?$ & OnOA1a \\
\hline 0.73937 & 94,06111 & 911.135335 & .00283 & .00403 \\
\hline 1.34030 & $9 \pm 074333$ & $94,1) 7881$ & inn336 & .00505 \\
\hline 1.54591 & $9+12770$ & 04.12010 & .00233 & .00511 \\
\hline 2.58903 & Q & 04.26806 & .010161 & .0053 ? \\
\hline
\end{tabular}


A8

Bond Index Rate of Return Regressed on Stock Market Index Rate of Return

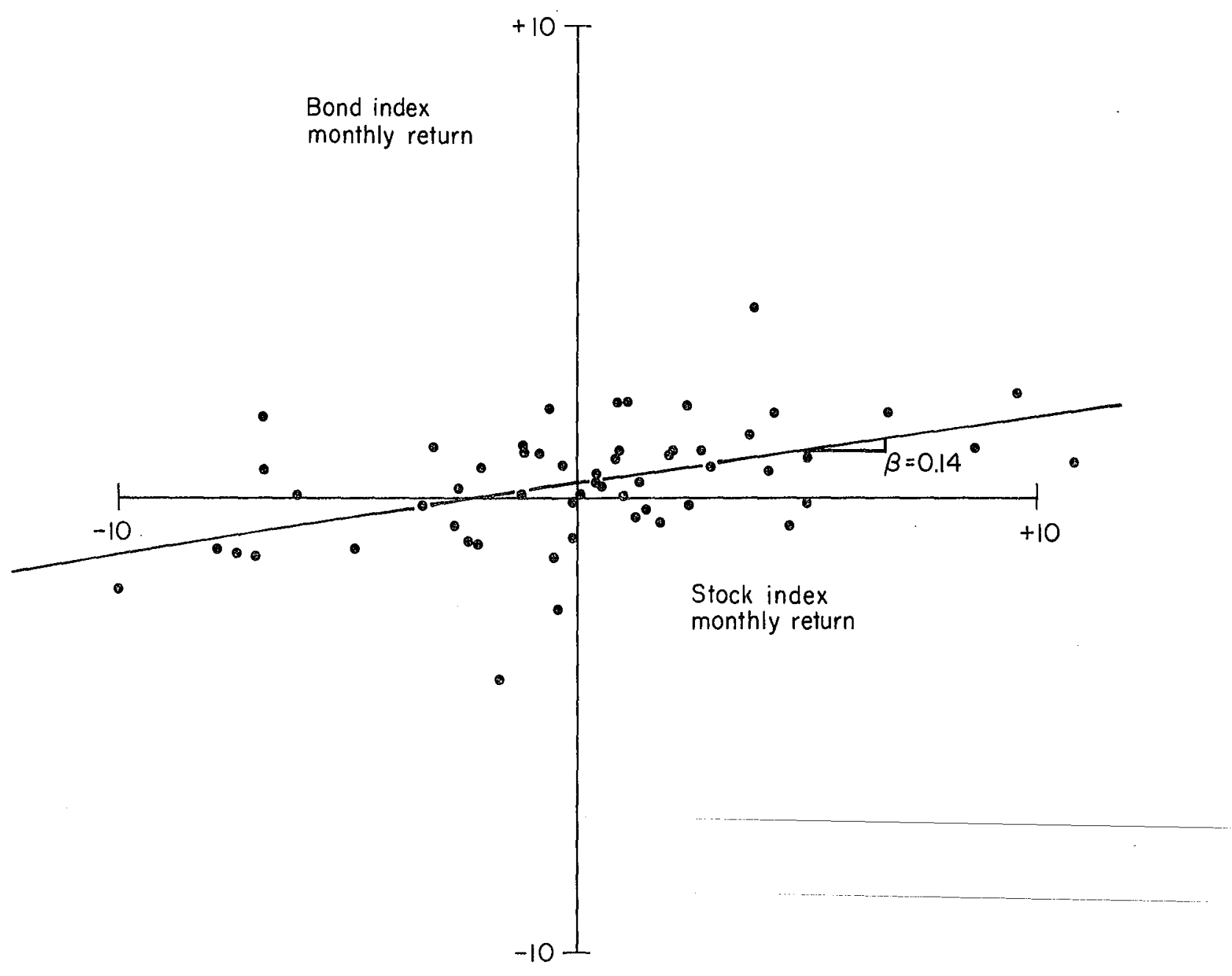

XBL $789-2678$ 
Tab1e A5-1

High Grade Corporate Bond Index Beta - Range of Variation as a Function of Averaging Interval

5 year Sliding Average

$$
\text { High }=0.223 \pm 0.054
$$

2.5 year S1iding Average

$$
\begin{array}{ll}
\text { High }=0.304 \pm 0.066 & \text { Fina } 1=0.231 \pm 0.071 \\
\text { Low }=0.008 \pm 0.059 &
\end{array}
$$

2 year Sliding Average

$\mathrm{High}=-0.342^{- \pm}-0.071$

Low $=0.025 \pm 0.071$

Final $=0.337 \pm 0.138$

1.5 year Sliding Average

$$
\begin{array}{ll}
\text { High }=0.432 \pm 0.158 & \text { Fina } 1=0.432 \pm 0.158 \\
\text { Low }=-0.083 \pm 0.091 &
\end{array}
$$

1 year Sliding Average

$$
\begin{aligned}
& \text { High }=0.621 \pm 0.174 \\
& \text { Low }=-0.132 \pm 0.140
\end{aligned} \quad \text { Fina }=0.252 \pm 0.209
$$


This report was done with support from the Department of Energy: Any conclusions or opinions expressed in this report represent solely' those of the author(s) and not necessarily those of The Regents of the University of California, the Lawrence Berkeley Laboratory or the Department of Energy. 


$$
+=
$$

TECHNICAL INFORMATION DEPARTMENT LAWRENCE BERKELEY LABORATORY

UNIVERSITY OF CALIFORNIA BERKELEY, CALIFORNIA 94720 